\title{
Mycosphere Essays 20: Therapeutic potential of Ganoderma species: Insights into its use as traditional medicine
}

\author{
Hapuarachchi $\mathrm{KK}^{1,2,3}$, Cheng $\mathrm{CR}^{4}$, Wen $\mathrm{TC}^{1^{*}}$, Jeewon $\mathbf{R}^{5}$ and Kakumyan $\mathbf{P}^{3}$ \\ ${ }^{1}$ The Engineering Research Center of Southwest Bio-Pharmaceutical Resources Ministry of Education, Guizhou \\ University, Guiyang 550025, Guizhou Province, China \\ ${ }^{2}$ Center of Excellence in Fungal Research, Mae Fah Luang University, Chiang Rai 57100, Thailand \\ ${ }^{3}$ School of Science, Mae Fah Luang University, Chiang Rai 57100, Thailand \\ ${ }^{4}$ Sichuan University of Science \& Engineering, Zigong, 643000, Sichuan Province, China \\ ${ }^{5}$ Department of Health Sciences, Faculty of Science, University of Mauritius, Reduit, 80837, Mauritius
}

Hapuarachchi KK, Cheng CR, Wen TC, Jeewon R, Kakumyan P 2017 - Mycosphere Essays 20: Therapeutic potential of Ganoderma species: Insights into its use as traditional medicine. Mycosphere 8(10), 1653-1694, Doi 10.5943/mycosphere/8/10/5

\begin{abstract}
The genus Ganoderma (Ganodermataceae) has a long history in traditional medicine to improve longevity and health in Asia. Ganoderma has been widely used in multiple therapeutic activities as well as dietary supplements to prevent and treat many diseases. Several classes of bioactive substances have been isolated and identified from Ganoderma, such as polysaccharides, triterpenoids, nucleosides, sterols, fatty acids, protein and alkaloids. There are numerous research publications, which report the abundance and variety of biological actions initiated by the metabolites of Ganoderma. Investigation on different metabolic activities of Ganoderma species has been performed both in vitro and in vivo. In many cases, however, it has been questioned whether Ganoderma is solely a nourishment supplement for wellbeing or merely a helpful "medication" for restorative purposes. There has been no any conclusive report of human trials using Ganoderma species as a direct control agent for diseases. In addition, there is no evidence supporting the usage of Ganoderma species (excluding G. lucidum) as potential supplements for cancer or other diseases in humans since no preclinical trials have been performed up to date. In this review, the beneficial medicinal properties of several species of Ganoderma (excluding $G$. lucidum) and their secondary metabolites are discussed. Ganoderma species can be used as a therapeutic drug, but more direct scientific evidence should be made available in the future. The efficiency of Ganoderma in clinical treatments should be substantiated with more biomedical research and their true impact assessed on human health with more standardized clinical evaluations so that the feasibility of biologically active extracts of Ganoderma species in alternative treatments can be recommended.
\end{abstract}

Key words - clinical evidence - medicinal properties - secondary metabolites

\section{Introduction}

Ganoderma P. Karst. 1881 is a group of wood degrading mushrooms with hard fruiting bodies, and species are generally not listed among edible mushrooms since their fruiting bodies are thick, corky and tough. They do not have the fleshy texture characteristics (Jong \& Birmingham 
1992, Jonathan et al. 2008). The genus Ganoderma was established by Karsten (1881) based on Ganoderma lucidum (Curtis) P. Karst. Donk (1948) introduced Ganodermataceae with the laccate and stipitate white rot fungus Polyporus lucidus W. Curtis as its type species (Moncalvo \& Ryvarden 1997) and placed the family in Polyporales, Basidiomycetes (Schwarze \& Ferner 2003). Ganoderma species have a worldwide distribution in green ecosystems both in tropical and temperate geographical regions (Pilotti 2005). These species grow as facultative parasites that can live as saprobes on rotting stumps and roots (Turner 1981). The sexual structure in Ganoderma is a basidiocarp and one of the two types of basidiocarps is produced, depending on the species: a laccate fruiting body with a shiny upper surface, or a non-laccate fruiting body with a dull upper surface (Kinge \& Mih 2014). Phytochemical and other studies reported varying species numbers in the genus (Li et al. 2013, Yan et al. 2013, Peng et al. 2014). Richter et al. (2015) suggested using a combination of morphological, chemotaxonomic and molecular methods to develop more stable taxonomy for the genus. However, the majority of species in genus Ganoderma has not subjected to systematic studies so far (Baby et al. 2015, Hapuarachchi et al. 2015, Zhou et al. 2015a).

Ganoderma is a genus of traditionally used, popular medicinal mushrooms that have been used particularly in China, Japan and Korea for millennia to improve longevity and health (Cheng et al. 2013b). There are a vast number of publications that report the abundance and variety of biological actions triggered by the primary metabolites of Ganoderma such as polysaccharides, proteins and triterpenes (Hapuarachchi et al. 2016a). Bioactive compounds from Ganoderma hold tremendous structural and chemical diversity (Yang et al. 2013, Hapuarachchi et al. 2016b). These bioactive constituents are reported to be responsible for the anti-cancer, anti-inflammatory, antitumor, anti-oxidant, immunomodulatory, immunodeficiency, anti-diabetic, anti-viral, anti-bacterial, anti-fungal, anti-hypertensive, anti-atherosclerotic, anti-aging, anti-androgenic, anti-hepatotoxic, radical scavenging property, neuroprotection, sleep promotion, cholesterol synthesis inhibition, hypoglycemia, inhibition of lipid peroxidation/oxidative DNA damage, hepatoprotective properties, maintenance of gut health, prevention of obesity, and stimulation of probiotics (Paterson 2006, Dai et al. 2009, Cheng et al. 2011, 2012a,b, 2013a, De Silva et al. 2012a,b, 2013, Cao \& Yuan 2013, Baby et al. 2015, Bishop et al. 2015, Liu et al. 2015b). Ganoderma has been used as functional food to prevent and treat many immunological diseases, such as anorexia, arthritis, asthma, bronchitis, cardiovascular problems, constipation, diabetes, dysmenorrhea, gastritis, hemorrhoids, hepatitis hypercholesterolemia, hypertension, insomnia, lupus erythematosis, migraine, nephritis, neurasthenia, neoplasia and tumorigenesis (Paterson 2006, Cheng et al. 2010, Liu et al. 2012, Wang et al. 2012a, Tan et al. 2015). However, it is not clear if the claimed benefits of taking various forms of Ganoderma are substantiated. In this review, we analyse various bioactive compounds produced by the Ganoderma species and their metabolic activities. We also present and discuss experimental evidence in connection with those species of Ganoderma and its beneficial medicinal properties. Table 1 lists common chemical compounds isolated from Ganoderma species.

\section{Beneficial medicinal properties of Ganoderma species}

\section{Ganoderma applanatum}

Some heterogalactans were found in aqueous extracts of G. applanatum (Fig. 1) (Usui et al. 1983) and further, exo polysaccharides and glucans were extracted from its fruiting bodies (Nakashima et al. 1979, Usui et al. 1983, Lee et al. 2007). Medicinal properties of G. applanatum are anti-tumor (Boh et al. 2000), aldose reductase inhibition (Lee et al. 2006), inhibition of EpsteinBarr virus activation (Chairul \& Hayashi 1994) and antibacterial activities (Smania et al. 1999). Anti-tumor activity against transplanted Sarcoma 180 in mice has been exhibited by the $\beta$-D-glucan polysaccharides from the basidiocarps of G. applanatum (Sasaki et al. 1971). Triterpenoids and malonate half-esters from the basidiocarps of G. applanatum inhibit tumor promotion (Tokuyama et al 1991, Lin et al. 1991). However, some esters showed toxicity at high concentrations (Chairul et al. 1990). Steroidal compounds from the basidiocarps were found to have broad-spectrum activities and bactericidal effects (Smania et al. 1999). Huie \& Di (2004) reported over 120 volati 
Table 1 Chemical compounds isolated from Ganoderma species.

G. ambionense (Lam.) Pat. trihydroxy-5 $\alpha$-ergosta-7,22-diene, Lucidone A

Ganoderic acid X and Ganodermacetal

Ganoderic acid AM, Ganoderic acid DM (Fig.6), Ganoderic acid F, Ganoderic acid H, Ganoderic acid P, Ganodermanontriol,

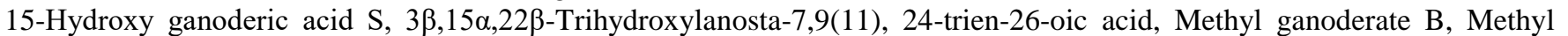
ganoderate $\mathrm{C}$ and Methyl ganoderate $\mathrm{E}$

G. annulare Lloyd) Boedijn 1940

Applanoxidic acid F, Applanoxidic acid C, Applanoxidic acid G, Applanoxidic acid H, Fungisterol (5 $\alpha$-ergost-7-en-3 $\beta$-ol),
Ergosta-7,22-dien-3 $\beta$-ol (stellasterol; 5,6-dihydroergosterol) and Ergosterol peroxide (5, 8-epidioxy-5 $\alpha$-8a-ergosta-6, 22Edien-3- $\beta$ ol

(24S)-24-Methyl-5 $\alpha$-cholest-7-ene-3 $\beta$-ol and (24S)-24-Methyl-5 $\alpha$-cholest-7, 16-diene-3 $\beta$-ol

Alnusenone, Furanoganoderic acid, Friedelin, Ganoderenic acid F, Ganoderenic acid G, Ganoderic acid B8, Ergosta-7,22 dien-3 $\beta$-ol (stellasterol; 5,6-dihydro-ergosterol), Methyl ganoderenate $\mathrm{H}$ and Methyl ganoderenate AP

Applanoxidic acid A and Applanoxidic acid B

Applanoxidic acid F, Applanoxidic acid G, Applanoxidic acid $\mathrm{H}$ and Applanoxidic acid E

$24 \xi$-Methyl-5 $\alpha$-lanosta-25-one and Ergosta-4, 6, 8(14), 22-tetraen-3-one

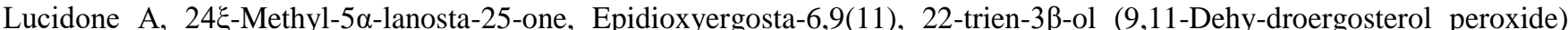
Ergosta-7, 22-dien-3-one and Ergosta-7, 22-dien-3 $\beta$-yl palmitate

Ergosterol, Ganoderenic acid A, Ganoderenic acid D, $\beta$-Amyrenone, $\beta$-Amyrin acetate, Ganoderma aldehyde and 2, 5 Dihydroxy benzoic acid

G. applanatum (Pers.) Pat.

Ergosterol; (24S) 24-methyl-5 $\alpha$-cholesta-7, 16-dien-3ß-ol; (24S) 24-methylcholesta-7, 22-dien-3-one (Ergosta-7, 22-dien-3one) as C28 sterols from G. applanatum

Methyl ganoderenate D, 23-Dihydroganoderenic acid I, 23-Dihydroganoderic acid N, 7ß-Hydroxy-3,11,15,23tetraoxolanosta-8,20E(22)-dien-26-oic acid, methyl ester $3 \beta, 7 \beta, 20,23 \mathrm{n}$-Tetrahydroxy-11,15-dioxolanosta-8-en-26-oic acid, $7 \beta, 20,23 \mathrm{n}$-Trihydroxy-3,11,15-trioxolanosta-8-en-26-oic acid and 7ß,23n-Dihydroxy-3,11,15-trioxolanosta-8,20E (22)-dien26-oic acid

D-mannitol, 2-methoxy fatty acids, cerebrosides, Daucosterol, 2, 5-Dihydroxyacetophenone, 2, 5-dihydro-xyacetophenone, 2,5-dihydroxybenzoic acid and Protocatechualdehyde

$3 \alpha$-Carboxyacetoxy-24-methylene-23-oxolanost-8-en-26-oic acid, 3 $\alpha$-Carboxyacetoxy-24-methyl-23-oxolanost-8-en-26-oic acid, $3 \alpha, 16 \alpha$-Dihydroxylanosta-7,9(11),24-trien-21-oic acid, 16 $\alpha$-Hydroxy-3-oxolanosta-7,9(11), 24-trien-21-oic acid and 3 $\alpha$, $16 \alpha, 26$-Trihydroxylanosta-7,9(11),24-trien-21-oic acid

Ergosterol peroxide (5,8-epidioxy-5 $\alpha$-8 $\alpha$-ergosta-6,22E-dien-3- $\beta$ ol $), \quad$ 22E,24R-Ergosta-7,22-diene-3 $\beta, 5 \alpha, 6 \beta$-triol

Lin et al. 1993

Li et al. 2005

Yang et al. 2012

Smania et al. 2003

Strigina et al. 1971

Nishitoba et al. 1989

Tokuyama et al. 1991

Yoshikawa et al. 2002

Chairul \& Hayashi 1994

Gan et al. 1998a

Gan et al. 1998b

Ming et al. 2002

Cole \& Schweikert 2003

Shim et al. 2004

Lee et al. 2005

De Silva et al. 2006 (Cerevisterol)

Lee et al. 2006 
Table 1 Continued.

G. applanatum (Pers.) Pat. 1887

Applanatine A, Applanatine B, Applanatine C, Applanatine D and Applanatine E and EchinolactoneD

Ganodermycin

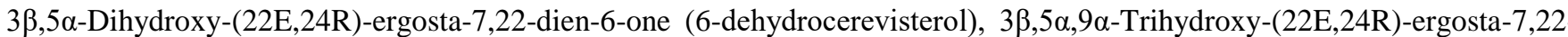
dien-6-one and $3 \beta, 5 \alpha, 6 \beta, 8 \beta, 14 \alpha-$-Pentahydr-oxy-(22E,24R)-ergost-22-en-7-one

G. atrum .D. Zhao, L.W. Hsu

\& X.Q. Zhang 1979

Ergosta-4,6,8(14),22-tetraen-3-one

Ergosta-7,22-dien-3-one, Fungisterol (5 $\alpha$-ergost-7-en-3 $\beta$-ol), Lanosta-7,9(11), 24-trien-3 $\beta, 21$-diol

Applanoxidic acid A, Applanoxidic acid F, Applanoxidic acid C, Applanoxidic acid G, Australic acid and Austrolactone,

Ergosterol, Ergosta-7,22-dien-3-ol, stellasterol (5,6-dihydroergosterol)

G. australe (Fr.) Pat. 1889

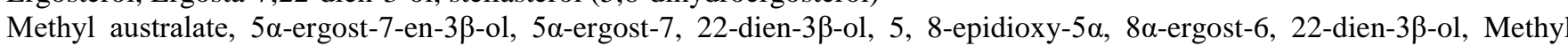

australate and Australic acid

Two laccase enzymes from G. australe

Fornicatin G (7 $\beta$-hydroxy-11-oxo-3, 4-seco-25, 26, 27-trinorlanosta-4(28),8-dien-24-oic-3-acetyl ester) Fornicatin $\mathrm{H}$

$3 \beta, 22 \mathrm{~S}-$ Dihydroxylanosta-7, 9(11), 24-triene

\section{G. boninense Pat. 1889}

Ergosterol

Ganoboninketal A, Ganoboninketal B, Ganoboninketal C

Fushimi et al. 2010

Jung et al. 2011

Lee et al. 2011

Shen et al. 2008

Jain \& Gupta 1984

León et al. 2003

Smania et al. 2007

Elissetche et al. 2007

Peng et al. 2012

Peng et al. 2014

Choon et al. 2011

Ma et al. 2014

Six new prenylated hydroquinones named Ganocalidin A-F and two new compounds of ganocalicineA and B together with

sixteen known compounds

Compounds Ganocalidin A and GanocalicineA

G. calidophilum J.D. Zhao, Ganoderma alkaloid A and Ganoderma alkaloid B

Huang et al. 2016b

L.W. Hsu \& X.Q. Zhang 1979

G. capense (Lloyd) Teng 1963

Two novel pyrrole alkaloids, Ganoine and Ganodine and a novel purine alkaloid Ganoderpurine

Yang \& Yu 1990

Yu et al. 1990

Carnosodione, 26, 27-Dihydroxylanosta-7, 9(11), 24-trien-3, 16-Dione. Ergosta-7, 22-dien-3ß-ol (stellasterol; 5, 6dihydroergosterol) and Ergosterol peroxide (5, 8-epidioxy-5 $\alpha$-8 $\alpha$-ergosta-6, 22E-dien-3- $\beta$ ol

$(+)$ - and (-)-cochlearols A and B, two meroterpenoids with novel polycyclic skeletons

G. carnosum Pat. 1889

G. cochlear (Blume \& T. Nees) Cochlate B, Fornicatin B, Fornicatin D, Fornicatin E, Fornicatin F, Friedelin, Ganocin A, Ganocin B, Ganocin C, Ganocin D,

Merr. 1917

Seven new prenylated phenols, five novel phenols with polycyclic skeleton and two new phenols with a carbon chain, along with one known compound were isolated from the fruiting bodies of Ganoderma cochlear

Colossolactone A Colossolactone B, Colossolactone C, Colossolactone D, Colossolactone E, Colossolactone F and

Colossolactone $\mathrm{G}$

Colossolactone I (22S)-3- $\beta$-hydroxylanosta-8,24-dien-26,22-olide), Colossolactone II (22S)-1,3- $\beta$-dihydroxylanosta-8,24dien-26,22-olide, Colossolactone III, Colossolactone IV, Colossolactone V, Colossolactone VI, Colossolactone VIII
Keller 1997

Dou et al. 2014

Peng et al. 2014

Peng et al. 2015b

Kleinwächter et al. 2001

El Dine et al. 2008
G. colossus
Baker 1920 
Table 1 Continued.

\section{G. colossus (Fr.) C.F.}

Baker 1920

Ganomycin B, Ganomycin I, farnesyl hydroquinone, Ganomycin I and another hydroquinone derivative Ganomycin B and schisanlactone A, Colossolactone VII, Ergosterol (El Dine et al. 2008) and Ganorbiformin A

Ganomycin B, Ganomycin I, farnesyl hydroquinone Ganomycin I and another hydroquinone derivative Ganomycin B and schisanlactone A

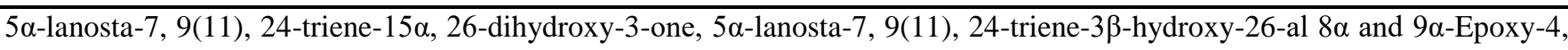

4, 14 $\alpha$-trimethyl-3, 7, 11, 15, 20-pentaoxo-5 $\alpha$-pregnane, Ganodermnonol, Ganodermadiol Ganoderic acid Y, Ganoderiol F,

Ganodermatriol, Ganodermanontriol, Ganoderiol A, Ganoderiol B and Fungisterol ( $5 \alpha$-ergost-7-en-3 $\beta$-ol), ergosta-7,22-dien3-one and ergosterol peroxide

G. concinnum Ryvarden 2000

$3 \beta, 12 \beta$-dihydroxy-7, 11, 15,23-tetraoxo-lanost-8,20-dien-26-oic acid, 15 $\alpha$-hydroxy-3,11,23-trioxo-lanost- 8,20-dien-26-oic

G. curtisii (Berk.) Murrill 1908 acid, $12 \beta$-acetoxy- 3,7,11,15,23-pentaoxo-lanost-8,20-dien-26-oic acid, 3 $\beta, 7 \beta, 12 \beta$-trihydroxy-11,15,23-trioxo-lanost-8,20dien-26- oic acid, $3 \beta, 7 \beta$ b,15a-trihydroxy-4- (hydroxymethyl)-11,23-dioxo-lanost-8-en-26-oic acid

Tsugaric acid

Fornicatin A and Fornicatin B

G. fornicatum (Fr.) Pat. 1889

Fornicin A, Fornicin B, Fornicin C and Fornicatin C

Lucidadiol, Ergosterol, Ergosterol peroxide (5 $\alpha, 8 \alpha$-epidioxy-ergosta-6, 22E-dien-3 $\beta$-ol) and Polycarp-ol T

Agnosterol, Ganoderic acid Y, Ganodermic acid T-Q Ganodermanondiol, 16 $\alpha$, 26-Dihydroxy lanosta-8, 24-dien-3-one,

Lucidenic acid A (Fig. 4), Lucidenic acid N (Fig. 4), Methyl lucidenate A and Methyl lucidenate N

G. hainanense J.D. Zhao,

L.W. Hsu \& X.Q. Zhang 1979

Ganohainanic acid A-E, acetyl ganohainanic acid A and D, Ganohainanic acid B, 3,7, 24-trioxo-5 $\alpha$-lanost-8, 25-dien-26-ol,

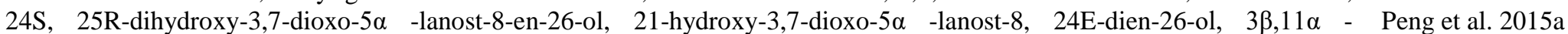
dihydroxy-7-oxo-5 $\alpha$-lanost-8,24E-dien-26-ol, Hainanic acid A and B, hainanaldehyde A

Sixteen new lanostane triterpenes, Ganoleucoins A-P with 10 known triterpenes

G. leucocontextum

Eighteen new lanostane-type triterpenoids, namely leucocontextins A-R

Six new lanostane-type triterpenoids, namely leucocontextins $\mathrm{S}-\mathrm{X}$

Spirolingzhines A-D, four meroterpenoids with a spiro[benzofuran-2, 1'-cyclopentane] motif, Lingzhines A-F, six meroterpenoids with diverse ring systems, along with two known compounds;

G. lingzhi T.H. Li, W.Q. Deng, Dong M. Wang \& H.P. Hu 2015 A new oxygenated la
Lingzhilactones A-C

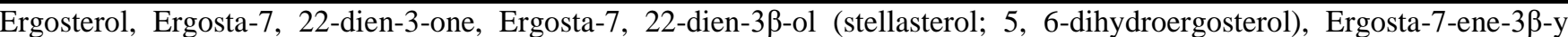

G. lipsiense sensu auct.

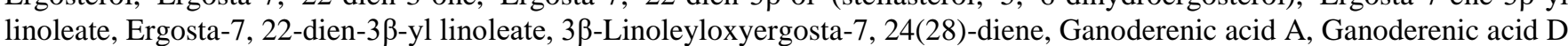
and their Methyl esters

Ganomastenol A, Ganomastenol B, Ganomastenol C, Ganomastenol D

G. mastoporum (Lév.) Pat. 1889 Ganomastenol, Ganomastenol B, Ganomastenol C, and Ganomastenol D Three triterpenoids and five steroids including ergosta-4, 6, 8(14), 22-tetraen-3-one
El Dine et al. 2009

Isaka et al. 2013

Gonzalez et al. 2002

Jiao et al. 2016

Lin et al. 1997

Niu 2004

Niu et al. 2006

Qiao et al. 2006

Ma et al. 2013

Wang et al. 2015

Zhao et al. 2016a

Zhao et al. 2016b

Yan et al. 2015

Rosecke \& Konig 2000

Hirotani et al. 1995

Cole \& Schweikert 2003

Thang et al. 2013 
Table 1 Continued.

Ganoderma species

Ergosta-7,22-dien-3-one, Ergosta-7,22-dien-3 $\beta$-ol (stellasterol; 5,6-dihydroergosterol), Ergosta-7,22-diene-2 $\beta, 3 \alpha, 9 \alpha$-triol and

Ergosta-7,22-dien-3 $\beta$-yl palmitate, Furthermore, two lanostanoids Ganoderal A (Fig. 4) and Ganodermadiol, steroid ( $2 \beta$, Gan et al. 1998b

G. neo-japonicum Imazeki $19393 \alpha, 9 \alpha$-trihydroxyergosta-7, 22-diene) and four ergosteroids

Two drimane-like sesquiterpenes known as Cryptoporic acids $\mathrm{H}$ and I

Paterson 2006

Five sterols (ergosta-7,22-dien-3 $\beta$-ol, ergosterol peroxide, ergosterol, cerevisterol, and ergosta-7, 22-dien-3-one), three

G. oerstedii (Fr.) Torrend 1902 terpene compounds (Ganodermanondiol, Ganoderic acid Sz, and Ganoderitriol M); From the mycelial culture two sterols (ergosterol and cerevisterol), and a new terpene compound (ganoderic acetate from the acid)

G. orbiforme ( $\mathbf{F r}_{\mathbf{r}}$ Ganoderic acid V, Ganorbiformin A, Ganorbiformin B, Ganorbiformin C, Ganorbiformin D, Ganorbiformin E,

$\begin{array}{ll}\text { G. orbiforme (Fr.) } & \text { Ganorbiformin F, Ganorbiformin G. Among the novel lanostane triterpenoids, ganorbiformins A-G, 7-O-Methyl ganoderic } \\ \text { Ryvarden } 2000 & \end{array}$ acid O, Ganoderic acid R, Ganoderic acid P, Ganoderic acid S, Ganodermic acid T-Q

G. petchii (Lloyd) Steyaert 1972 (-)-Petchioics A and B (1 and 2), Petchiates A and B (3 and 4), Petchine and a known compound Petchienes A-E, five new meroterpenoids 2,5-dihydroxy benzoic acid and 2,4,5-trihydroxy benzaldehyde, Linolic acid and $\beta$-1, 3-glucans

Applanoxidic acid A (Fig. 4), Applanoxidic acid C, Ergosta-7,22-dien-3-one, Ergosta-7, 22-dien-3ß-ol (stellasterol; 5, 6dihydroergosterol), Ergosterol peroxide (5, 8-epidioxy-5 $\alpha$ - $8 \alpha$-ergosta-6, 22E-dien-3- $\beta$ ol, Ergosta-4, 6, 8(14), 22-tetraen-3-one, Lucialdehyde B, Lucialdehyde D, Ganoderol A, Ganoderol B (Fig. 4), Ganoderone A and Ganoderone C.

G. pfeifferi Bres. 1889 Ganomycins A and B

Ganodermadiol, Lucidadiol, and Applanoxidic acid G

Lucialdehyde D, Ganoderone A, and Ganoderone C. Ganoderone A and Lucialdehyde B, (and ergosta-7,22-dien-3b-ol)

1-octen-3-ol (amyl vinyl carbinol), 1-octen-3-ol acetate, phenylacetaldehyde and 6-camphenol

Mendoza et al. 2015

Isaka et al. 2013

Gao et al. 2015

Al-Fatimi 2001

Niedermeyer et al. 2005

Mothana et al. 2000

Mothana et al. 2003

Niedermeyer et al. 2005

Al-Fatimi et al. 2016

Sixteen compounds were isolated by 2, 5-dihydroxyacetophenone, methyl gentisate, (S)-dimethyl malate, muurola-4, 10 (14)-

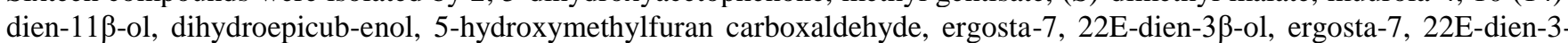

G. philippi (Bres. \& Henn. ex Sacc.) Bres. 1932

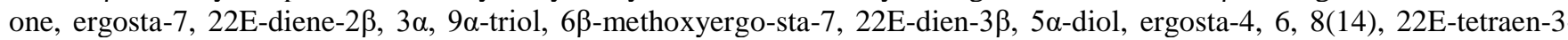
one, ergosta4, 6, 8-(14), 22E-etetraen-3 $\beta$-ol, $5 \alpha, 8 \alpha$-epidioxy-ergosta-6, 22E-dien-3 $\beta$-ol, $7 \alpha$-methoxy- $5 \alpha, 6 \alpha$-epoxyergosta-8-

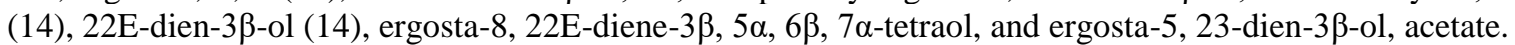

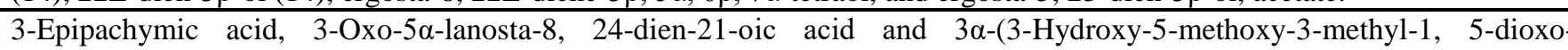
pentyloxy)-24-methylene-5 $\alpha$-lanost-8-en-21-oic acid

7-Oxo-ganoderic acid Z, 7-Oxo-ganoderic acid Z2, 7-Oxo-ganoderic acid Z3, Ganoderic acid Y, Ganoderesin B, Ganoderesin A, Lucidone D, Lucidone E, Lucidone F, Lucidone G and Lucidone H
Niu et al. 2007

Peng et al. 2013 
Table 1 Continued.

Ganoderma species

Ergosta-7,22-dien-3 $\beta$-ol, ergosterol, 6, 9-epidi-oxyergosta-7, 22-dien-3beta-ol, 5, 8-epidioxiergosta-6, 22-dien-3beta-ol, ergosta-7, 22-dien-3-one, $\beta$-sitosterol (6), $\alpha$-Hydroxytetracosanoic acid, cyclo (D-Pro-D-Val)

Ganoderiol A triacetate, Ganolactone B, Lucidenolactone, Ganolactone B

Liu et al. 2007

Ergosta-7, 22-dien-3 $\beta$-ol (stellasterol; 5,6-dihydroergos-terol), Ergosterol peroxide (5,8-epidioxy-5 $\alpha$ - $8 \alpha$-ergosta- $6,22 \mathrm{E}-$ dien-3-

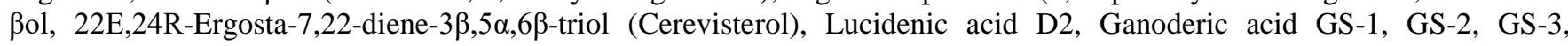
Ganoderic acid $\beta$, Ganoderiol A, Ganodermanontriol, Ganosinensin A, Ganosinensin B, Ganosinensin C, 20-Hydroxy

G. sinense J.D. Zhao, L.W. lucidenic acid A, 20-Hydroxy lucidenic acid N, 20(21)-Dehydrolucidenic acid A, 20(21)-Dehydrolucidenic acid N

Hsu \& X.Q. Zhang 1979

Methyl ganosinensate A, Ganosinensic acid A, Ganosinensic acid B

Sinensine, Sinensoic acid

Ganoderiol J, Ganoderiol E, Ganolucidic acid B, Ganolucidic acid $\gamma$ a, Ganolucidate F, Ganoderic acid Jc, Ganoderic acid Jd, Ganosinoside A, Sinensine B, Sinensine C, Sinensine D and Sinensine E

Ganosinensine, Ganosineniol A, Ganodermatetraol, Lucidadiol, Lucidumol B, Methyl lucidenate Ha, Tsugarioside A (3aacetoxy-5 $\alpha$-lanosta-8, 24-dien-21-oic acid ester $\beta$-D-glucoside), 20(21)-Dehydrolucidenic acid N and 20-Hydroxylucidenic acid A

G. theaecola J.D. Zhao 198

Five new lanostane triterpenoids, Ganoderic acid XL1, Ganoderic acid XL2, 20-hydroxy-ganoderic acid AM1, Ganoderenic acid AM1 and Ganoderesin C, and five other known triterpenoids

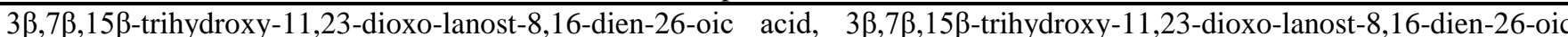
acid methyl ester, and 3 $\beta, 15 \beta$-dihydroxy-7,11,23-trioxo-lanost-8,16-dien-26-oic acid methyl ester

Qiao et al. 2007

Sato et al. 2009b

Wang et al. 2010

Liu et al. 2010

Liu et al. 2011

Liu et al. 2012

Liu et al. 2014

Hu et al. 2013

26-Nor-11, 23-dioxo-5 $\alpha$-lanost-8-en-3 $\beta, 7 \beta 15 \alpha, 25$-tetrol, 3 $\beta, 7 \beta, 15 \beta$-Trihydroxy-11, 23-dioxo-lanost-8, 16-dien-26-oic acid

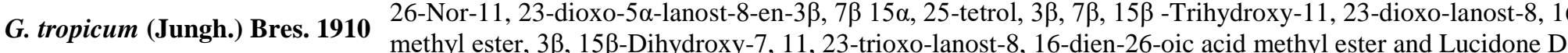

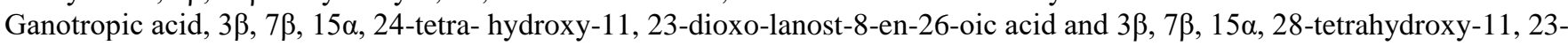
dioxo-lanost-8, 16-dien-26-oic acid

Lucidone A, Lucidenol

Three antitumor-active polysaccharides

Tsugaric acid A, Tsugaric acid B, Ergosta-7, 22-dien-3ß-ol (stellasterol); 5,6-dihydroergosterol;

G. tsugae Murrill 1902

Two novel lanostanoids, $3 \alpha$-acetoxy-5 $\alpha$-lanosta-8, 24-diene-21-oic acid (tsugaric acid A) and 3 $\alpha$-acetoxy-16 $\alpha$-hydroxy-24- Lin et al 1997 methyl-5 $\alpha$-lanosta-8, 25-diene-21-oic acid (tsugaric acid B)

Ergosta-7,22-diene-2 $\beta, 3 \alpha, 9 \alpha$-triol

New lanostanoid ester glucoside, 3R-acetoxy-5R-lanosta-8, 24-dien-21-oic acid ester $\beta$-D glucoside and a known steroid, $2 \beta$, 3R, 9R-trihydroxy-5R-ergosta-7, 22-diene

Zhang et al. 2015

Su et al. 1993

Mizuno 1995

Lin et al 1997

Gan et al. 1998a

Gan et al. 1998a 
Table 1 Continued.

Ganoderma species

Tsugarioside B, Tsugarioside A and 3 $\beta$-Hydroxy-5 $\alpha$-lanosta-8,24-dien-21-oic acid;

3-oxo-5 $\alpha$-lanosta-8,24-dien-21-oic acid, Oxo-5 $\alpha$-lanosta-8,24-dien-21-oic acid and $2 \beta, 3 \alpha$, 9 $\alpha$-trihydroxy-5 $\alpha$-ergosta-7,22diene, Tsugaric acid $\mathrm{C}$, Tsugarioside $\mathrm{C}$;

$(24 R, S)$-3R-acetoxy-24-hydroxy-5R-lanosta-8,25-dien-21-oic acid, named tsugaric acid C, 3R-acetoxy-5R-lanosta-8,24diene-21-O- $\beta$-D-xyloside, named tsugariosi-de B, and 3R-acetoxy- (Z)-24-methyl-5R-lanosta-8,23,25-trien-21-oic acid ester $\beta$-D-xyloside, named tsugarioside $\mathrm{C}$, and a mixture of two known steroids

Lucidenic acids and Colossolactones A

Ganoderic acids A, B, C1, C5, C6, D, E, G and Ganoderenic acid D

G. tsugae Murrill 1902

Two novel heteropolysaccharides (EPF1 \& EPF2) from the crude extracellular polysaccharide

Peng et al. 2003

Extracted a novel water soluble polysaccharide-protein complex

Peng \& Zhang 2003

Six water-soluble polysaccharides

Peng et al. 2005

Ganodone

La Clair et al. 2011

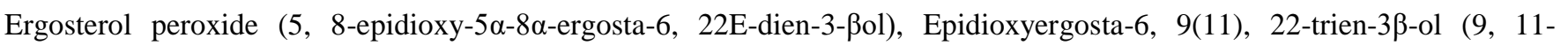
Dehydroergosterol peroxide)

Tsugaric acid D and Tsugaric acid $\mathrm{E}$

$3 \beta$-acetoxy-16 $\alpha$-hydroxy-24 $\xi$-methyl-5 $\alpha$-lanosta-8,25-dien-21-oic acid, named tsugaric acid $\mathrm{F}$ and a novel palmitamide, $\mathrm{N}$ (3' $\alpha, 4$ ' $\beta$-dihydroxy-2' $\beta$-(hydroxymethyl)-1' $\beta$-(cyclobutyl) palmitamide

flavor compounds, mostly alcohols, aldehydes, ketones, esters, phenols, and very-long-chain fatty acids with more than 23 carbon atoms from $G$. applanatum at trace levels (1-2\%). Water-soluble preparations from carpophores of G. applanatum exhibited potent antiviral activity against vesicular stomatitis virus Indiana serotype VSV (IND) (Zjawiony 2004).

In vitro evaluation of antioxidant activities of $G$. applanatum showed significant inhibition of lipid peroxidation, and potent hydroxyl radical scavenging activity when compared with the standard drug Catechin. Furthermore, crude, boiled and ethanolic extracts also significantly increased nitric oxide production over the control (Acharya et al. 2005). Studies of Jung et al. (2005) suggested that G. applanatum might possess constituents with antidiabetic and inhibitory effects on diabetic complications. Polysaccharides of G. applanatum (PGA) could strengthen gastric mucosa barrier by improving the level of PGE2, GMBF and the secretion of gastric mucus, which may be one of the mechanisms underlying the protective effect of PGA on the gastric mucosa during the gastric ulcer (Yang 2005). Bhattacharyya et al. (2006) demonstrated in vitro antimicrobial activity against Acitenobacter aerogenes, Acrobacter aerogenes, Arthrobacter citreus, Bacillus brevis, B. subtilis, Corynebacterium insidiosum, Escherichia coli, Proteus vulgaris, Clostridium pasteurianum, Micrococcus roseus, Mycobacterium phlei, Sarcina lutea and Staphylococcus aureus. Moradali et al. (2007) reported antibacterial activity only against gram-negative bacteria. The antitumor effect of exo-biopolymer (EXP) produced was investigated 
using sarcoma-180 bearing mice. EXP, when administered (10-80 mg/kg body weight: BW) intraperitoneally, significantly inhibited the growth of solid tumor and increased the natural killer (NK) cell activity (Jeong et al. 2008).

CXCL10 (inducible protein-10) contributes for the actions of macrophages and Tlymphocytes, and helps in chronic inflammatory conditions. Ganodermycin, isolated from fermentations of G. applanatum inhibited lipopolysaccharide (LPS)/interferon (IFN)- $\gamma$-induced CXCL10 promoter activity in transiently transfected MonoMac6 cells. Ganodermycin reduced LPS/IFN- $\gamma$-induced CXCL10 protein synthesis and excretion (Junget al. 2011).

Ganoderma applanatum extract could enhance the sensitivity of SGC-7901 cells to the c-jun, p53, Bax and Bcl-2 induced apoptosis and provided a promising approach to anti-human gastric cancer therapy (Ma et al. 2011). Trigos \& Medelline (2011) mentioned that Applanoxidic acids A, B C, D, E, F, G and H, isolated from a non-polar fraction of this fungus, proved to be effective against skin tumors in mice. Furthermore, it has been reported that extracts have an inhibitory effect on metaloendopeptidase encefalinase EC 3.4.24.11, a potential application for pain treatment. Vazirian et al. (2014) showed considerable anti-inflammatory effects due to polysaccharide components ( $\beta$-glucan) of the extracts. Ganoderma applanatum mycelium extracts and its active component, Protocatechualdehyde (PCA) may suppress adipogenesis by inhibiting differentiation of 3T3-L1 preadipocytes, and in part through altered regulation of PPAR $\gamma, \mathrm{C} / \mathrm{EBP} \alpha$, and SREBP1 in order to confirm anti-obesity property (Kim et al. 2014).

Reports from Osińska-Jaroszuket al. (2014) revealed that, exopolysaccharide preparation of G. applanatum (GpEPS) may exhibit selective activity against tumor cells (cell lines $\mathrm{SiHa}$ ) and stimulate production of TNF- $\alpha$ THP-1-derived macrophages. Moreover, the GpEPS showed antibacterial properties against $S$. aureus and a toxic effect against Vibrio fischeri cells. Further, GpEPS showed high cholesterol-binding capacity and triglycerides-binding capacity. FGAP and SGAP were typical polysaccharides with different molecular weights, monosaccharide components, and functional groups isolated from G. applanatum and FGAP exhibited a better antitumor activity than SGAP. Inhibition of CSGAP against Sarcoma 180 in vivo was significantly enhanced by comparison to the native SGAP and even higher than that of FGAP, suggesting that the carboxylate groups played a major role in antitumor activity of $G$. applanatum polysaccharide (Sun et al. 2014). A $\beta$-carotene-degrading enzyme activity was observed in liquid cultures and the new enzymes may replace common bleaching agents to produce environmentally more compatible detergent formulations (Lanfermann et al. 2015).

Exopolysaccharides could scavenge hydroxyl radicals (HR) and superoxide anion radicals (SAR), and the concentration of exopolysaccharides was positively related to the antioxidant activity (Liu et al. 2015c). Applanatumin A, a novel meroterpenoid dimer, exhibited potent antifibrotic activity in TGF- $\beta 1$-induced human renal proximal tubular cells (Luo et al. 2015). Aqueous extracts from fruiting bodies are also active against influenza viruses (Teplyakova \& Kosogova 2015). The ethanol and methanol extract of $G$. lipsiense (synonymized as $G$. applanatum) showed antibacterial activity against Vibrio cholera (Singdevsachan et al. 2015).

Zengin et al. (2015) revealed methanol and water extracts of G. applanatum possess weak antibacterial and antifungal activities. Spiroapplanatumines A-Q, along with three known compounds, spirolingzhines $\mathrm{A}, \mathrm{B}$, and $\mathrm{D}$, were isolated from the fruiting bodies of the fungus. Moreover, Spiroapplanatumines $\mathrm{G}$ and $\mathrm{H}$ compounds inhibited JAK3 respectively (Luo et al. 2017). ( \pm )-Ganoapplanin a pair of novel meroterpenoid enantiomers was isolated from $G$. applanatum. Biological studies showed that $( \pm)-1$ and its enantiomers exhibited different inhibitory activities on T-type voltage-gated calcium channels ( $\mathrm{Li}$ et al. 2016a). Manayi et al. (2016) suggested the potential ability of $G$. applanatum aqueous extract to activate immunologic parameters in rainbow trout fish. Crude exopolysaccharides from G. applanatum (GpEPS) can be safely used in anticancer therapy without side effects or damage to healthy cells (Prendecka et al. 2016). Ganoderma lipsiense extract could inhibit malignant proliferation of tumor cells by suppressing angiogenesis of blood vessels in tumor tissues and regulating cell cycles, thereby 
inhibiting triple-negative breast cancer (TNBC) cell line MDA-MB-231-HM in a mouse model (Qi et al. 2016).

\section{Ganoderma amboinense}

Lanostanoid triterpenesisolated from G. amboinense (Fig. 3) inhibited the growth of numerous cancer cell lines, and the activities of topoisomerases I and IIa ( $\mathrm{Li}$ et al. 2005). Furthermore, Ganoderic acid X inhibits topoisomerases and sensitizethe cancer cells toward apoptosis and acts as a potential anti-cancer drug. Ganoderma amboinense has been shown to exert a preventive effect on acetaminophen-induced acute liver injury (Hsu et al. 2008).

\section{Ganoderma atrum}

Chen et al. (2007) found that G. atrum (Fig. 3) polysaccharide (PSG-1) had strong antioxidant potential based on in vitro evaluation of the free radical-scavenging and self-oxidation of 1, 2, 3-phentriol inhibitory activities, which may be comparable to vitamin C. PSG-1 protects cardiomyocytes against oxidative stress induced by anoxia/reoxygenation by attenuating ROS production, apoptosis and increasing activities and protein expressions of endogenous antioxidant enzymes (Li et al. 2009). PSG-1 significantly attenuates anoxia/reoxygenation-induced oxidative stress and improves cell survival in cardiomyocytes through mitochondrial pathway, furthermore it inhibited tumor growth in S180-bearing mice via the induction of apoptosis and immunoenhancement effects through the same pathway ( $\mathrm{Li}$ et al. 2010a) and also enhanced the cyclophosphamide-induced anti-tumor effect ( $\mathrm{Li}$ et al. 2011a). Administration of PSG-1 significantly reduced apoptosis in the mouse brain in a dose-dependent manner. PSG-1-evoked reduction of apoptosis was associated with the decrease of MDA and GSSG contents, and the increase of SOD, CAT, GPx and GSH-Rd activities, and GSH contents. PSG-1 treatment was also found to attenuate ROS production and calcium accumulation ( $\mathrm{Li}$ et al. 2011b). PSG-1 significantly decreased lipid peroxidation in liver, brain, and spleen, but concomitantly increased the activities of superoxide dismutase, catalase, and glutathione peroxidase compared with the d-gal group. Elevation of glutathione contents and attenuation of glutathione disulfide contents were also found in PSG-1-treated animals. Furthermore, the results showed that PSG-1 treatment increased basal lymphocyte proliferation as well as $\mathrm{T}$ cell and $\mathrm{B}$ cell proliferation and enhanced interleukin-2 production (Li et al. 2012a).

Ethanol-soluble acidic components (ESAC) exhibited antimicrobial activity against bacteria (S. aureus, E. coli, B. subtilis and P. vulgaris), and exerted antioxidant activities by 2,2-diphenyl-1picrylhydrazyl (DPPH) radical scavenging, total reducing power and $\beta$-carotene bleaching assays. ESAC (at concentrations of $0-100 \mu \mathrm{g} / \mathrm{mL}$ ) did not show any cytotoxic effects in RAW264.7 murine macrophage cells ( $\mathrm{Li}$ et al. 2012b). Mitogen-activated protein kinase (MAPK) pathways were simultaneously activated and involved in PSG-1-induced TNF- $\alpha$ secretion in RAW264.7 cells and phosphoinositide 3-kinase (PI3K)/Akt pathway was stimulated and played an important role in the PSG-1 induced TNF- $\alpha$ secretion. Nuclear factor (NF)- $\kappa$ B activation by PSG-1 was triggered by $\mathrm{PI} 3 \mathrm{~K} / \mathrm{Akt} / \mathrm{MAPK}$ pathway and NF- $\mathrm{KB}$ participated in PSG-1 stimulated TNF- $\alpha$ production. This showed the potential of PSG-1 as a novel immunomodulating agent (Yu et al. 2012a). Ganoderma atrum polysaccharide increased the production of NO, and the level of mRNA expression of inducible nitric oxide synthase in a dose-response manner and polysaccharide dose-dependently induced the release of TNF- $\alpha$ and interleukin-1 $\beta$. Generation of reactive oxygen species was promoted by PSG-1. Furthermore, PSG-1 induced nuclear factor- $\kappa \mathrm{B}$ activation by elevation of $\mathrm{p} 65$ nuclear translocation, suggesting that PSG-1 probably stimulated macrophage activities by activating the nuclear factor- $\mathrm{kB}$ pathway (Yu et al. 2012a).

Zhang et al. (2013a) found PSG-1 increased macrophage phagocytosis and the levels of cytokines and nitride oxide through TLR4-mediated NF- $\kappa$ B and MAPK signaling pathways in S180 tumor bearing mice model. Furthermore, a similar mode of action was demonstrated, as polysaccharides did not kill CT26 colorectal carcinoma cells directly but exerted inhibitory effects on proliferation of CT26 cells by activating peritoneal macrophages and tumor growth was also 
inhibited in mice with CT26 xenografts (Lin et al. 2015). Zhu et al. (2013) revealed oral administration of PSG-1 at 200 or $400 \mathrm{mg} / \mathrm{kg}$ body weight significantly reduced fasting blood glucose and serum insulin levels. Moreover, PSG-1 significantly decreased the levels of serum total cholesterol, triglyceride, low-density lipoprotein cholesterol, free fatty acid and insulin resistance, and increased high-density lipoprotein cholesterol level and insulin sensitivity. PSG-1 inhibited the expression of pro-apoptotic protein, Bax and increased the expression of anti-apoptotic protein, Bcl-2 in pancreatic cells, suggesting that PSG-1 exerted a protective role in the pancreas of diabetic rats. Chen et al. (2014) was able to modify a water-soluble polysaccharide (PSG) extracted from $G$. atrum to obtain its acetylated and carboxymethylated derivatives and then evaluated their antioxidant and immunomodulatory activities in vitro and characterized the relationship between bioactivity and chemical characteristics.

PSG-1 induced apoptosis in CT26 cells and enhances the antitumor immune response, induces apoptosis in CT26-bearing mice, and could be a safe and effective adjuvant for tumor therapy or functional food. Furthermore, PSG-1 could inhibit the tumor growth, possibly in part by enhancing the induction of apoptosis through cAMP-PKA signaling pathway and down-regulation of $\mathrm{Ca}(2+) / \mathrm{PKC}$ signal pathway, activating host immune function in S180-bearing mice (Zhang et al. 2014). PSG-1 induces TNF- $\alpha$ secretion through TLR4/ROS/PI3K/Akt/MAPKs/NF- $\kappa$ B pathways during macrophage activation and thus provides a molecular basis for the potential of PSG-1 as a novel immunomodulatory agent (Yu et al. 2014a). Yu et al. (2014b) revealed PSG-1 treatment accelerated recovery dose-dependently of peripheral red blood cells, white blood cells and platelets, enhanced splenic natural killer cell activity and cytotoxic T lymphocyte activity in Cy-treated mice. PSG-1 elevated CD4 (+) T lymphocyte counts and CD4 (+)/CD8 (+) ratio dose-dependently. Furthermore, PSG-1 restored the levels of IL-2, INF- $\gamma$, IL-10, IgA, IgM and IgG and hemolysin in the sera. PSG-1 can also significantly increase the total antioxidant capacity, activities of superoxidase dismutase, catalase and glutathione peroxidase, and decrease the malondialdehyde level in vivo. Zhu et al. (2014) revealed that the protective effects of PSG-1 against endothelial dysfunction may be related to activation of the PI3K/Akt/eNOS pathway. Ganoderma atrum sulfated polysaccharides with C-2 position (S-PSG-2) derived could be served as immunomodulator and free-radical inhibitors (Chen et al. 2015). Huang et al. (2016a) revealed that PSG-1stimulated macrophages resulted in an increase in phosphorylation of NF- $\kappa \mathrm{B}$, Akt and MAPK family proteins, which are indicative of activations of NF- $\kappa B$ pathway activation. Furthermore, the levels of TNF- $\alpha$ protein and TNF- $\alpha$ mRNA expression were significantly suppressed when macrophages were pretreated with various inhibitors, including NF-kB inhibitors, IkB inhibitors, MAPK inhibitors and PI3K/Akt inhibitors.

Li et al. (2015) revealed PSG-1 in reactive oxygen species (ROS) generation and mitochondrial function in hyperglycemia-induced angiopathy. PSG-1, mPTP blocker, or caspase inhibition can reduce apoptosis and ROS generation. Experimental results show that exposure of survival of human umbilical vein cells (HUVECs) to $35.5 \mathrm{mmol} / \mathrm{L}$ glucose increases the proportion of cells undergoing apoptosis. PSG-1 also increases mitochondrial Bcl-2 protein formation and mitochondrial membrane potential $(\Delta \Psi \mathrm{m})$ but inhibits Bax translocation, cytochrome $\mathrm{c}$ release, and caspase activation. Lin et al. (2015) revealed that polysaccharides isolated from $G$. atrum considerably enhanced cell surface expression of Toll-like receptor-4 in macrophages and induced intracellular signaling. In vitro tests showed that sulfated modification of water-insoluble polysaccharide from $G$. atrum improved its antioxidant activities and anti-proliferative ability against S-180 tumor cells (Zhang et al. 2015).

PSG-1 may induce activation of spleen lymphocytes at least in part via the $\mathrm{Ca} 2+/ \mathrm{CaN} / \mathrm{NFAT} / \mathrm{IL}-2$ signaling pathway and the PKC/NFAT/IL-2 signaling pathway cooperatively regulated PSG-1-induced activation of spleen lymphocytes. Furthermore, the antitumor activity of PSG-1 is mediated by Toll-like receptor 4 (TLR4) (Yu et al. 2015). There was evident nuclear accumulation of the p65 subunit of NF- $\kappa B$ and degradation of I $\mathrm{B} \alpha$. FIP-gat, an immunomodulatory protein isolated from G. atrum, is a new member of the FIP family. This protein could reduce MDA-MB-231 cells cell viability dose-dependently with a median inhibitory 

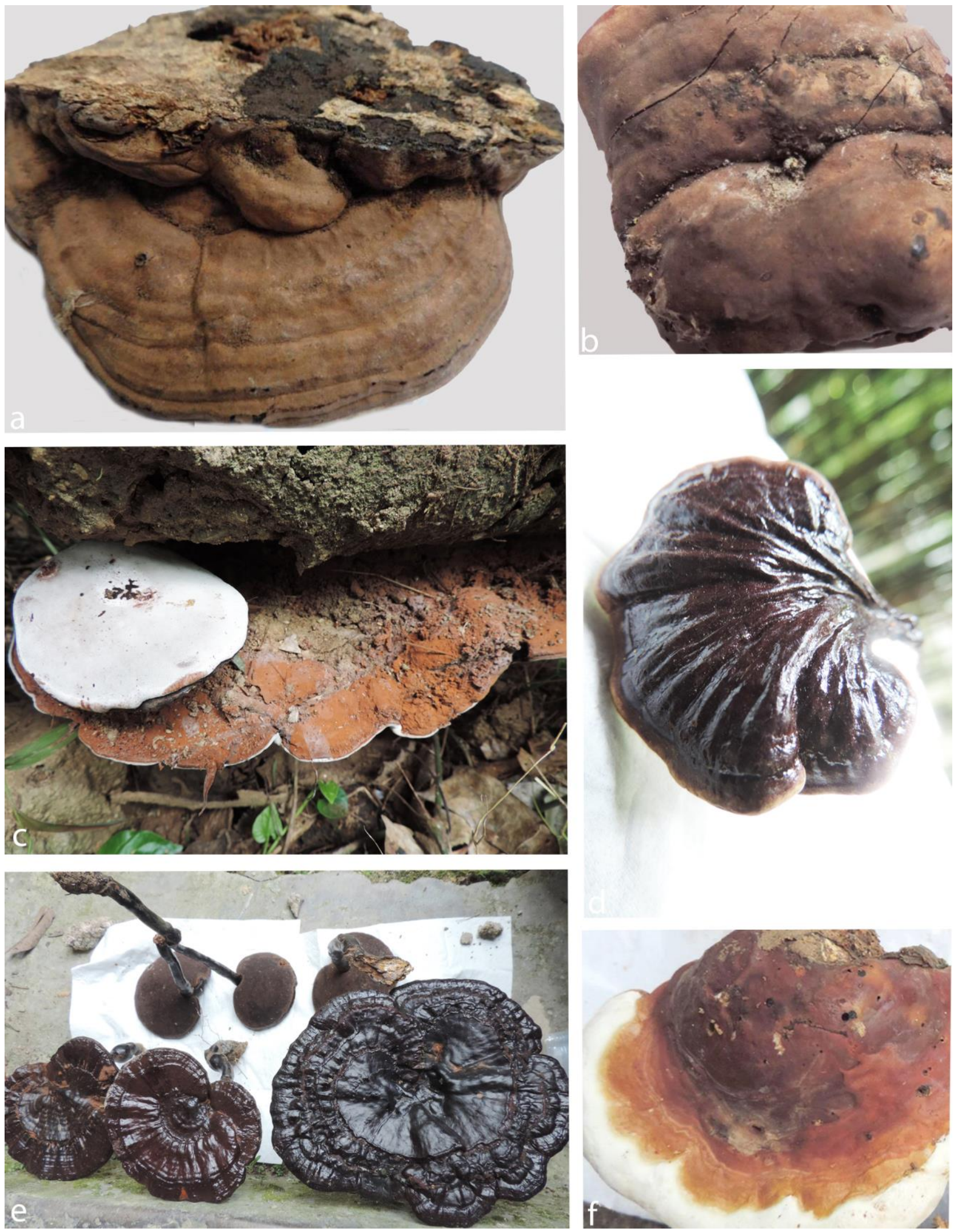

Figure 1 - Medicinally important Ganoderma species. a Ganoderma australe (GACP 14081321). b G. annulare (GACP HNU5456). c G. applanatum (GACP 14081511). d G. calidophilum (GACP HNU86). e G. sinense (GACP 14081236). f G. tropicum (GACP 14081328). 

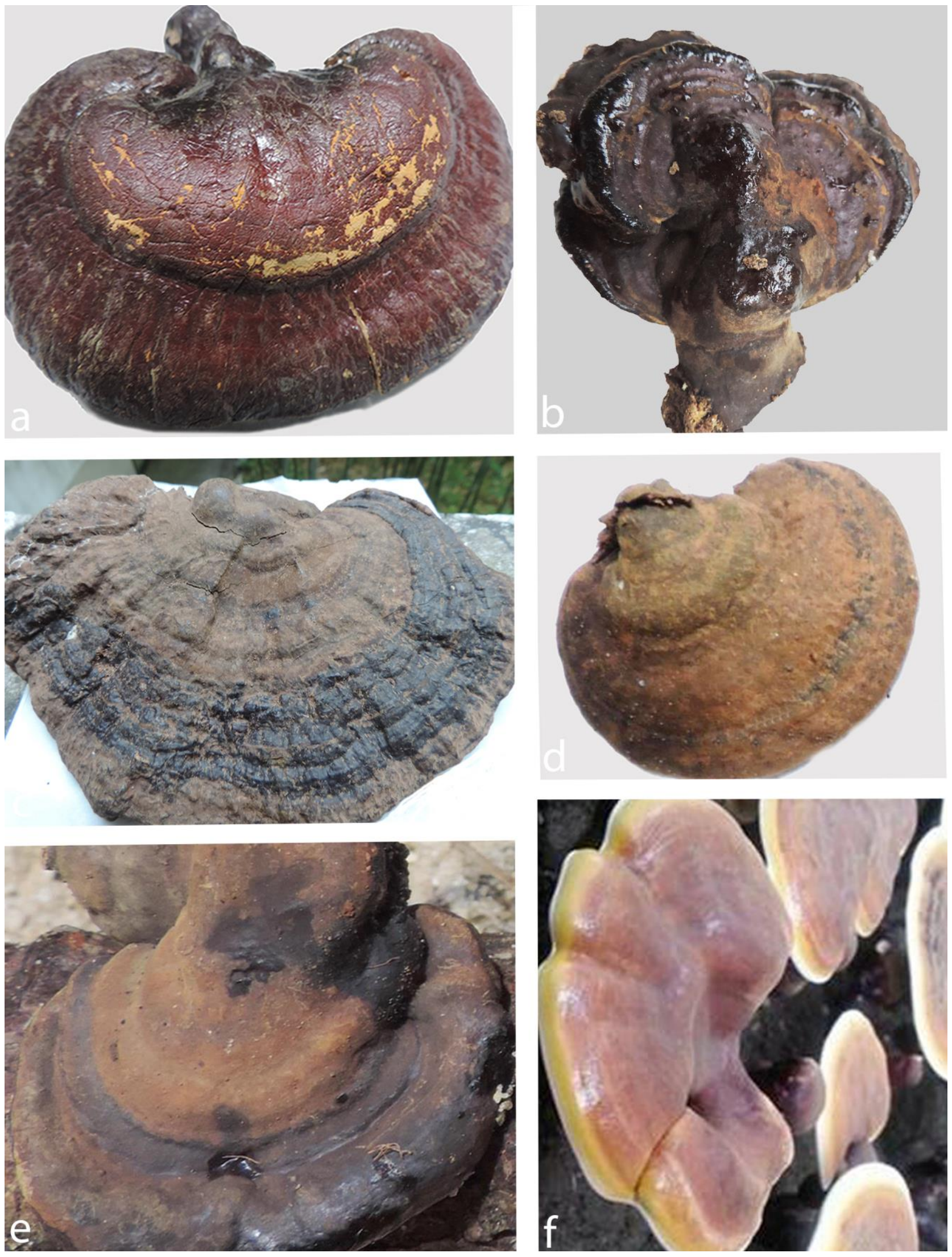

Figure 2 - Medicinally important Ganoderma species. a G. lingzhi (GACP HNU10). b G. fornicatum (GACP 14081329). c G. orbiforme (GACP14081310). d G. mastoporum (GACP 14081136). e G. fornicatum (GACP 14081136). f G. leucocontextum (www.cembn.com) [accessed 22 February 2017]. 

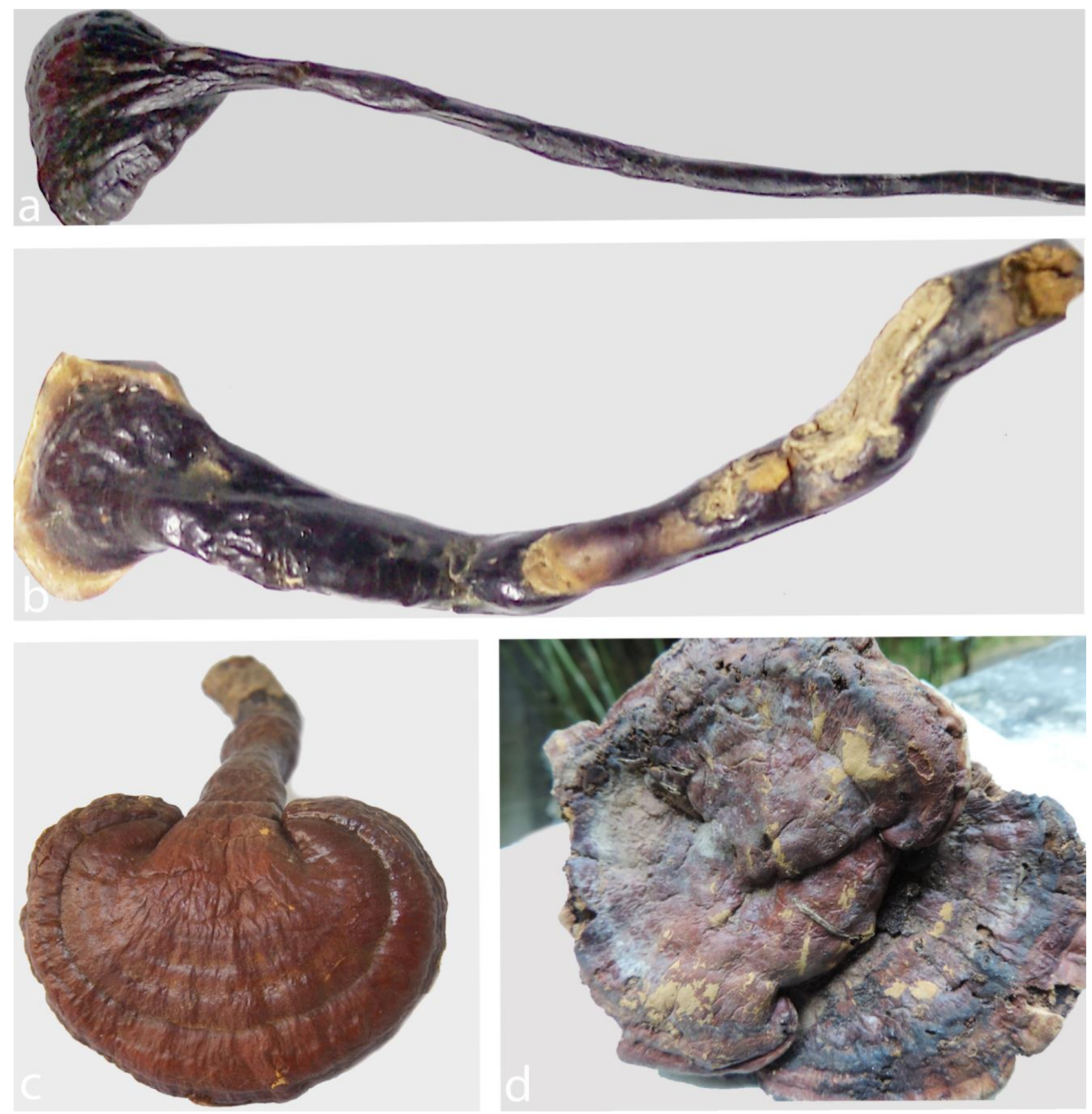

Figure 3 - Medicinally important Ganoderma species. a Ganoderma atrum (GACP 16072832). b G. amboinense (GACP 16082544). c G. neo-japonicum (GACP 17072725). d G. tropicum (GACP HNU21). *GACP - The Herbarium of Guizhou University

concentration $\left(\mathrm{IC}_{50}\right)$ of $9.96 \mu \mathrm{g} / \mathrm{mL}$ and agglutinate the MDA-MB-231 cells at a concentration as low as $5 \mu \mathrm{g} / \mathrm{mL}$. Furthermore, FIP-gat at a concentration of $10 \mu \mathrm{g} / \mathrm{mL}$ can induce significant growth inhibition and cell death in MDA-MB-231 cells. FIP-gat treatment triggers significant cell cycle arrest at the G1/S transition and pronounced increase in apoptotic cell population (Xu et al. 2016).

Zhu et al. (2016) revealed PSG-1 decreased the activities of serum aspartate aminotransferase (AST) and alanine aminotransferase (ALT), while increasing hepatic glycogen levels. PSG-1 also exerted strong antioxidant activities, together with unregulated mRNA expression of peroxisome proliferator-activated receptor- $\gamma$ (PPAR- $\gamma$ ), glucose transporter-4 (GLUT4), phosphoinositide 3kinase (PI3K), and phosphorylated-Akt (p-Akt) in the liver of diabetic rats. The improvement of PSG-1 on liver function in type 2 diabetic rats may be due to its antioxidant effects, SCFA 
excretion in the colon from PSG-1, and regulation of hepatic glucose uptake by inducing GLUT4 translocation through PI3K/Akt signaling pathways. Five new lanostanoid triterpenes were isolated from the ethanol extract of the fruiting bodies of $G$. atrum. Two of the isolated compounds exhibited potent neuroprotective activity against 6-OHDA-induced cell death in SH-SY5Y cells while other compounds possessed significant neuroprotective activity. All tested compounds showed the comparable free radical scavenging activities with the standard drug trolox in both ABTS (+) and DPPH experiment (Qiu et al. 2016). PSG-1 protected mice against CTX-mediated immunosuppression, as evidenced by enhancing the ratios of thymus and spleen weights to body weight, promoting T cell and B cell survival, and increasing levels of TNF- $\alpha$ and IL-2. Apoptosis, ROS generation and lipid peroxidation in the immune organs of the immunosuppressed animals were ameliorated by PSG-1 and further, it may play an important role in PSG-1-evoked immune protection. Hence, these findings have demonstrated that PSG-1 may ameliorate CTX-induced immunosuppression through reducing apoptosis and oxidative damage in immunological system (Li et al. 2017a).

Mannose receptor (MR) was crucial for the immune response to a Ganoderma atrum polysaccharide (PSG-1), as evidenced by elevation of MR in association with increase of phagocytosis and concentrations of interleukin-1 $\beta$ (IL-1 $\beta$ ) and tumor necrosis factor- $\alpha$ (TNF- $\alpha$ ) in normal macrophages. Elevation of MR triggered by PSG-1 also led to control lipopolysaccharide (LPS)-triggered inflammatory response via the increase of interleukin-10 (IL-10) and inhibition of phagocytosis and IL-1 $\beta$ (Li et al. 2017b).

\section{Ganoderma australe}

Ganoderma australe (Fr.) Pat. (Fig. 1) has triterpenoids with cytostatic activity against tumor cells (León et al. 2003). Both australic acid and methyl australate have antibacterial and antifungal activities against bacteria and fungi. Elissetche et al. (2007) isolated two laccase enzymes from $G$. australe and the former has been reported to have potential antibacterial activities (Luna-Acosta et al. 2011). De Melo et al. (2016) revealed the biological effect of the $\beta$-glucan from G. australe via in vitro cell cultures of peritoneal macrophages isolated from Swiss mice. Biological assays confirmed that there was an increase in interleukin- 6 by approximately $111 \%$ with $1.0 \mu \mathrm{g} / \mathrm{mL}$ of polysaccharide, and phagocyte activity was increased in all concentrations examined, obtaining $52.3 \%$ with $0.25 \mu \mathrm{g} / \mathrm{mL}$ polysaccharide. The results indicate that a $\beta-(1 \rightarrow 3)$-glucan isolated from G. australe can be classified as a biological response modifier. Applanoxidic acid A isolated from G. annulare (synonymized as G. australe) showed weak antifungal activity against Trichophyton mentagrophytes which are well known to occur as dermatophytes (Smania et al. 2003).

\section{Ganoderma capense}

Isolation of nucleotides and nucleosides from the mycelia of $G$. capense was first reported in 1979 by Yu \& Zhai (Huie \& Di 2004). Uridine and uracil were found to be capable of lowering the serum aldolase level of mice, suffering from experimental Myotonia. Adenosine has also been shown to inhibit platelet aggregation (Shimizu et al. 1985). Lanosta-7, 9(11), 24-trien-3 $\beta, 15 \alpha, 22-$ triacetoxy-26-oic acid showed mitogenic activities toward mouse splenocytes and anti-proliferative activity toward leukemia cells and hepatoma cells in vitro. The lectin exhibited more potent mitogenic activity than that of concanavalin A (Ngai \& Ng 2004). A novel water-soluble polysaccharide (GCP50-1) was obtained from the dried powder of submerged fermentation mycelia of G. capense by extraction with hot water ( $\mathrm{Li}$ et al. 2013). Preliminary anti-radical in vitro studies of Yan et al. (2013) indicated that the four crude polysaccharides showed concentration-dependent scavenging abilities on DPPH and hydroxyl radicals. GCGP (G. capense Glycopeptide) had inflammatory modulation effects on macrophage cells to maintain NO production and iNOS expression at the normal level and the underlying mechanism of immunomodulatory effect of GCGP involved NF- $\kappa$ B p65 translation, I $\kappa$ B phosphorylation, and degradation. Furthermore, GCGP could inhibit LPS from binding to macrophage cells (Zhou et al. 2014). 
Jiang et al. (2016) revealed a novel polysaccharide, designated as GCPB-1b, from the alkaline extract of the submerged fermentation culturing mycelium powder of $G$. capense. Furthermore, GCPB-1b had 1-diphenyl-2-picryl-hydrazyl (DPPH) radical-scavenging ability according to antioxidant activity tests which was greater than other antioxidants. These data suggest that GCPB-1b holds promise as an anti-aging functional food. Eight aromatic meroterpenoids including Ganocapensins A and B were isolated from G. capense. All isolated compounds showed significant antioxidant effects with $\mathrm{IC}_{50}$ values ranging from $6.00 \pm 0.11$ to $8.20 \pm 0.30 \mu \mathrm{g} / \mathrm{ml}$ in the DPPH radical scavenging assay (Peng et al. 2016). Huang et al. (2015) revealed a novel heteropolysaccharide (GCPB-2), isolated from the submerged fermentation culturing mycelia powder G. capense. In the in vitro antioxidant assay, GCPB-2 was found to possess 1-diphenyl-2picryl-hydrazyl (DPPH) radical-scavenging activity, which provided an experimental evidence to support G. capense as a functional food in some Asian countries.

\section{Ganoderma colossus}

Kleinwächter et al. (2001) extracted triterpenoids from a Vietnam specimen named $G$. colossum and they mentioned this species was synonymised as Polyporus colossus and Dendrophagus colossus. This was subsequently followed by few researchers (El Dine et al. 2008, 2009, Weng et al. 2010, Ofodile et al. 2012). However, according to Index Fungorum (accessed 22 February 2017) the latter species were synonymized as G. colossus not as G. colossum. Therefore, we used the accepted scientific species name to avoid confusion. Colosolactones from G. colossus showed moderate cytotoxicity against L-929, K-562 and HeLa cells. As well, $3 \alpha$-hydroxysteroid

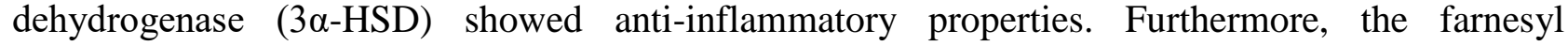
hydroquinone Ganomycin I and another hydroquinone derivative Ganomycin B and schisanlactone A isolated from G. colossus showed significant anti-HIV activity (Kleinwächter et al. 2001). Colossolactone E, Colossolactone V, and colossolactone VII inhibit HIV-1 protease with IC50 values of 8.0, 9.0, and $13.8 \mathrm{lg} / \mathrm{mL}$, respectively (El Dine et al. 2008). When HepG2 cells were treated with the ethanol extract of $G$. colossus (EEGC), the PMA-induced invasion was reduced in a dose-dependent manner and the PMA-induced matrix metalloproteinase (MMP)-9 was also suppressed at the transcriptional level. The EEGC also showed an inhibitory effect on the PMAinduced phosphorylation of extracellular signal-regulated kinase (ERK1/2) and protein kinase B (Akt) in cytosol, as well as the activator protein-1 (AP-1) and nuclear factor-kappa B (NF-kappa B) levels in the nucleus of HepG2 cells. This study provides the first evidence demonstrating that the EEGC is an effective inhibitor on the PMA-induced invasion of hepatoma cell. The EEGC could be further tested by an in vivo model to verify whether it is effective for the prevention of hepatoma invasion or metastasis (Weng et al. 2010). Ofodile et al. (2012) isolated and tested antimicrobial activity of three Colossolactones, colossolactone E, colossolactone $B$ and 23hydroxycolossolactone $\mathrm{E}$. The results showed that colossolactone $\mathrm{E}$ and 23-hydroxycolossolactone E were active against B. subtilis and Pseudomonas syringae, however, colossolactone B was not active against the bacteria.

\section{Ganoderma cochlear}

(+)- and (-)-cochlearols A and B, two meroterpenoids with novel polycyclic skeletons, were isolated from the fruiting bodies of the fungus $G$. cochlear. Biological studies showed that (-) cochlearols are strong inhibitors of p-Smads, exhibiting renoprotective activities (Dou et al. 2014). All compounds found by Peng et al. (2015b) showed antioxidant effects in radical scavenging assays via a plausible biosynthetic pathway. Wang et al. (2016b) reported six novel meroterpenoids cochlearoids F-K using isolated by utilizing phytochemical approaches. Biological evaluation shows that compounds exhibit potent inhibitory activity on fibronectin overproduction in TGF- $\beta 1$ induced HKC-8 cells. Seven pairs of new alkaloid enantiomers, Ganocochlearines C-Iand three pairs of known alkaloids were isolated from the fruiting bodies of G. cochlear (Wang et al. 2016c).

Ganoderma calidophilum, G. carnosum, G. chalceum and G. concinnum 
Ganoderma calidophilum (Fig. 1) is a rare wild fungus in the Ganodermataceae family, distributed in tropical areas of China, and its fruiting body is traditionally used to treat allergic asthma, eczema, and allergic rhinitis. Compounds Ganocalidin A and GanocalicineA showed inhibitory activityeffects on $\beta$-hexosaminidase activity and significantly reduced the production of IL-4 and LTB4 by RBL-2H3 cells in response to antigen stimulation and therefore demonstrated anti-allergic activity (Huang et al. 2016b). Akar et al. (2006) reported utilization of a macro-fungus $G$. carnosum as a biosorbent material for the removal of lead (II) ions from aqueous solutions. Water, Methanol and Ethanol extracts of G. chalceum showed selective antibacterial activity against $P$. aeruginosa and $E$. coli. The spent mushroom substrate of $G$. balabacense (synonymized as $G$. chalceum) cultivation (SMSGB) contains a large amount of bioactive substances. Hot water extract with SMSGB treatment is effective in improving milk yield and hematology parameters of dairy cows, and may be useful as a functional feed additive (Liu et al. 2015a).

Gonzalez et al. (2002) isolated lanosta triterpenoids from a species named Ganoderma concinna. These isolated triterpenoids exhibit apoptosis-inducing activity against myeloid leukemia HL-60 cells. In contrast, three triterpenoids from $G$. concinnum inhibited calf and rat DNA polymerases implicated in DNA repair, recombination and DNA replication (Mizushina et al. 1999).

\section{Ganoderma formosanum, G. fornicatum and G. hainanense}

Wang et al. (2011) revealed that D-mannose and D-galactose are the major constituents of $G$. formosanum polysaccharides. Furthermore, they demonstrated extracellular polysaccharides of this mushroom have the potential to be used as immuno-stimulatory and antibacterial agents against Listeria monocytogenes injected in mice. Extracellular polysaccharides produced by $G$. formosanum stimulate macrophages via the engagement of multiple pattern-recognition receptors including Dectin-1, CR3 and TLR4, resulting in the activation of Syk, JNK, p38, ERK, and NK-кB and the production of TNF- $\alpha$ (Wang et al. 2012b). PS-F2, a polysaccharide fraction purified from the submerged culture broth of $G$. formosanum, stimulates the activation of dendritic cells and primes a $\mathrm{T}$ helper 1 (Th1)-polarized adaptive immune response. BALB/c mice were sensitized by repeated immunization with chicken ovalbumin (OVA) and alum, followed by intranasal challenge of OVA to induce acute asthma. PS-F2 administration during the course of chicken ovalbumin (OVA) sensitization and challenge effectively prevented AHR development, OVA-specific IgE and IgG1 production, bronchial inflammation, and Th2 cytokine production. Hence, PS-F2 has a potential to be used for the prevention of allergic asthma (Pi et al. 2014a).

PS-F2 functions as an adjuvant capable of inducing a Th1-polarized adaptive immune response, which would be useful in vaccines against viruses and tumors ( $\mathrm{Pi}$ et al. 2014b). The polysaccharide fraction purified from a culture broth of $G$. formosanum has been shown to have notable anticancer activity. When administered intraperitoneally or orally, the polysaccharide fraction efficiently inhibited tumor growth in xenografted mice (Wang et al. 2014). The three prenylated phenolic compounds extracted from G. fornicatum (Fig. 2) Fornicin A Fornicin B and Fornicin C showed moderate cytotoxic activity in Hep-2 cells (Qiao et al. 2006). Li et al. (2016b) showed five new lanostane-type triterpenoids, ganoderenses A-E (two new lanostane nortriterpenoids, ganoderenses $\mathrm{F}$ and $\mathrm{G}$ ) along with 13 known analogues were isolated from the fruiting body of $G$. hainanense. All compounds were evaluated for inhibitory activity against thioredoxin reductase (TrxR), a potential target for cancer chemotherapy with redox balance and antioxidant functions.

\section{Ganoderma leucocontextum}

Some Ganoleucoins and triterpenes extracted from G. leucocontextum (Fig. 2) showed much stronger inhibitory activity against HMG-CoA reductase and few presented potent inhibitory activity against $\alpha$-glucosidase. Furthermore, the cytotoxicity was exhibited against the K562 and PC-3 cell lines by the MTT assay with $\mathrm{IC}_{50}$ values in the range 10-20 $\mu \mathrm{M}$ (Wang et al. 2015). Leucocontextins R exhibited weak cytotoxicity against K562 and MCF-7 cell lines with $\mathrm{IC}_{50}$ of 20- 
$30 \mu \mathrm{M}$. Wang et al. (2016d) found three new meroterpenoids, Ganoleucin A-C, together with five known meroterpenoids from the fruiting bodies of Ganoderma leucocontextum. Ganomycin I showed stronger inhibitory activity against HMG-CoA reductase than the positive control atorvastatin. Other compounds presented potent noncompetitive inhibitory activity against $\alpha$ glucosidase from both yeast and rat small intestinal mucosa. Ganomycin was synthesized and evaluated for its in vivo bioactivity. Pharmacological results showed that Ganomycin I exerted potent and efficacious hypoglycemic, hypolipidemic, and insulin-sensitizing effects in KK-Aymice.

\section{Ganoderma lingzhi}

Tran et al. (2014) used G. lingzhi's own proteases to hydrolyze its protein and obtained autodigested Reishi (ADR) extract to determine its potential for use as a hypotensive medication. The results showed that ADR could be a good source of hypotensive peptides that could be used for antihypertensive medication or incorporation into functional foods. Yan et al. (2015) revealed Lingzhilactone B could inhibit ROS generation in a dose-dependent manner, inhibit mRNA expression of collagen IV, fibronectin, IL-6 and increase expression of Nrf 2 in rat tubular epithelial cells. The in vitro and in vivo results suggested that Lingzhilactone B could protect against renal injuries by increasing the activities of antioxidants and inhibiting inflammation. The inhibition of Smad3 phosphorylation suggested that this substance displays in vivo anti fibrotic activity by a mechanism that is dependent on disruption of Smad3. Studies of Fatmawati et al. (2013) revealed a series of lanostane-type triterpenoids, identified as Ganoderma alcohols and Ganoderma acids from the fruiting body of G. lingzhi. Some of these compounds were confirmed as active inhibitors of the in vitro human recombinant aldose reductase. Structure-activity studies of Ganoderma alcohols showed that the $\mathrm{OH}$ substituent at C-3 and the double-bond moiety at C-24 and C-25 are necessary to increase $\alpha$-glucosidase inhibitory activity. The structure-activity relationships of Ganoderma acids revealed that the $\mathrm{OH}$ substituent at $\mathrm{C}-11$ is an important feature and that the carboxylic group in the side chain is essential for the recognition of $\alpha$-glucosidase inhibitory activity. Moreover, the double-bond moiety at C-20 and C-22 in the side chain and the $\mathrm{OH}$ substituent at C-3 of Ganoderma acids improve $\alpha$-glucosidase inhibitory activity.

Lucidumol $\mathrm{C}$ showed potent selective cytotoxicity against HCT-116 cells and high cytotoxic activities against Caco-2, HepG2 and HeLa cell lines (Amen et al. 2016). Twenty nine lanostane triterpenoids were obtained from the EtOH extract of fruiting bodies of $G$. curtisii including a new lanostane triterpenoid and four known other compounds were isolated from the genus Ganoderma for the first time (Jiao et al. 2016). Wang et al. (2016c) revealed the triterpene acid extract (TAE) from G. lingzhi mycelia was found to be cytotoxic to the SMMC-7721 and SW620 cell lines in vitro, and the TAE exhibited dose-dependent antitumor activity against the solid tumor sarcoma 180 in vivo. Chemical analysis revealed that the key active triterpene compounds, Ganoderic acid T (Fig. 4) and ganoderic acid Me, predominated in the extract. Amen et al. (2017) suggest that the traditional uses of G. lingzhi might be in part due to the ROCK-I and ROCK-II inhibitory potential of this mushroom. Structure-activity relationship studies revealed lanostane triterpenes potentiate their Rho-kinase inhibition.

Zhang et al. (2017) revealed Ganoderic acids (GAs) in G. lingzhi exhibit anticancer and antimetastatic activities. GA yields can be potentially improved by manipulating G. lingzhi through genetic engineering. In this study, a putative lanosterol synthase (LS) gene was cloned and overexpressed in G. lingzhi. Results showed that its overexpression (OE) increased the ganoderic acid (GA) content and the accumulation of lanosterol and ergosterol in a submerged G. lingzhi culture. This study demonstrated that OE of the homologous LS gene could enhance lanosterol accumulation. A large precursor supply promotes GA biosynthesis.

\section{Ganoderma microsporum}

A new recombinant immunomodulatory protein (GMI) was purified from G. microsporum (Fig. 4), with anti-metastatic effect and it can inhibit epidermal growth factor mediated migration and invasion in A549 lung cancer cells (Lin et al. 2010). GMI induces lung cancer cell death by 
activating autophagy, but does not induce apoptotic cell death. Using VZV-G pseudotyped lentivirus-shRNA system for autophagy-related genes silencing, the capabilities of GMI to reduce cell viability and colony formation were abolished in autophagy-defective cells. Furthermore, GMI did not stimulate apoptosis after blocking of autophagy by 3-MA or shRNA knockdown system. Oral administration of GMI inhibited the tumor growth and induced autophagy significantly in nude mice that had received a subcutaneous injection of A549 cells (Hsin et al. 2011).

Autophagosome accumulation induces autophagic cell death in a GMI, and ATP6V0A1 plays an important role in mediating autophagosome-lysosome fusion (Hsin et al. 2012). GMI, elevates the intracellular calcium level and reduces the growth of MDR subline via autophagy and apoptosis, regardless of p-glycoprotein (P-gp) overexpression, in mice xenograft tumors. Furthermore, autophagy plays a pro-death role in acquired MDR and upregulation of autophagy by GMI via Akt/mTOR inhibition provides a potential strategy for overcoming MDR in the treatment of lung cancers (Chiu et al. 2015). GMI and cisplatin induce apoptosis via autophagy/caspase-7dependent and survivin- and ERCC1-independent pathway. GMI may be a potential cisplatin adjuvant against lung cancer (Hsin et al. 2015).

\section{Ganoderma orbiforme and G. mastoporum}

The C-3 epimer of ganoderic acid T isolated from G. orbiforme (Fig. 2) exhibited significant antimycobacterial activity with Mycobacterium tuberculosis H37Ra (Isaka et al. 2013). Ergosta-4, 6, 8(14), 22-tetraen-3-one (3) by G. mastoporum (Fig. 2) exhibited the most significant inhibition towards superoxide anion generation and elastase release (Thang et al. 2013).

\section{Ganoderma neo-japonicum}

The Malaysian indigenous tribes use G. neo-japonicum (Fig. 3) to treat various diseases such as asthma, cancer, diabetes, epilepsy and fever. Lin et al. (1995) demonstrated that the scientific validation of the medicinal value of this mushroom has not been extensively investigated and has been reported as a potent radical scavenger and showed hepatoprotective activity in vivo. The therapeutic effect of $G$. japonicum mixture on thrombosis and its mechanism were studied. The results showed that G. japonicum mixture inhibited thrombus formation in vitro and in vivo (Wen et al. 1997). Methionine enhanced the Ergothioneine by using the mycelia culture of $G$. neojaponicum (Lee et al. 2009). Production Tryptophan was the best amino acid in accumulation of total phenolic compound in the mycelial culture of G. neo-japonicum (Park \& Lee 2010).

This mushroom has strong $\beta$-glucosidase and avicelase activities (Jo et al. 2011a). Jo et al. (2011b) performed an experiment to determine the laccase activity for G. neo-japonicum and results revealed that optimum detection of cellulase activity was reported at $25{ }^{\circ} \mathrm{C}$ for Congo red dye at $\mathrm{pH}$ 7.0. Wheat grains fermented by mycelia of G. neo-japonicum enhanced antioxidant activities and adipogenesis (Tan et al. 2015) and that PPAR $\gamma$ expression in 3T3-L1 cells was modulated (Subramaniam et al. 2014, 2015). The aqueous extracts of $G$. neo-japonicum had a significant effect on neurite outgrowth stimulatory activities when compared to nerve growth factor (Seow et al. 2013). The aqueous extracts of basidiocarps of $G$. neo-japonicum showed the involvement of MEK/ERK1/2 and P13K/Akt signaling pathways for neuritogenesis in PC-12 cells in-vitro (Seow et al. 2013).

\section{Ganoderma pfeifferi}

Sterols from G. pfeifferi (Komoda et al. 1989) and oxygenated triterpenes (Shiao 2003) have been shown to inhibit cholesterol synthesis in vitro. Mothana (1999) first reported the anti-bacterial activity of $G$. pfeifferi. His studies demonstrated $\mathrm{CH}_{2} \mathrm{Cl}_{2}, \mathrm{EtOH}$ and hot aqueous extracts of the fruiting bodies of the mushroom exhibited antibacterial activity against Gram-positive (B. subtilis, S. aureus, S. epidermides and Micrococcus flavus) and Gram-negative (E. coli, Proteus mirabilis, Pseudomonas aeruginosa, P. maltophilia and Serratia marcescens) bacteria. Furthermore, these extracts from $G$. pfeifferi also inhibited the growth of the fish pathogenic bacteria Aeromonas hydrophila and A. salmonicida, while the hot aqueous extract was also active against fish 
pathogenic species Vibrio anguillarum and Yersinia ruckeri (Mothana 1999, Mothana et al. 2000). Ganomycins A and B, from G. pfeifferi exhibited antibacterial activity against Gram-negative and Gram-positive bacteria (Mothana et al. 2000). Al-Fatimi (2001) revealed 2, 4, 5-trihydroxy Benzaldehyde isolated from $G$. pfeifferi inhibited the growth of Gram-positive and Gram-negative bacteria, fish pathogenic bacteria and yeasts and the compound was active against multi-resistant strains of S. aureus and enterococci. 2, 5-Dihydroxy benzoic acid exhibited no antibacterial activity, but showed antifungal activity against Candida maltosa. Lanostane type triterpenes named Ganodermadiol, Lucidadiol, and Applanoxidic acid G from G. pfeifferi have also been shown to exhibit activity against HSV-1 and influenza A virus (Mothana et al. 2003).

Four sterols and 10 triterpenes from the fruiting bodies of $G$. pfeifferi were isolated, including three new triterpenes: Lucialdehyde D, Ganoderone A, and Ganoderone C. Ganoderone A and Lucialdehyde B, (and ergosta-7, 22-dien-3 $\beta$-ol) were found to exhibit potent inhibitory activity against herpes simplex virus (Niedermeyeret al. 2005). The analysis of antiviral activity of the extract of G. pfeifferi against influenza virus type A, HSV-1, HIV-1, revealed that the major antiviral component of the extract were triterpenoids: Ganodermadiol, Lucidadiol and Aplanoxin acid G (Teplyakova \& Kosogova 2015). Farnesyl hydroquinone and Ganomycin K were also reported from this mushroom and the former have not been shown any antibacterial activity while the latter showed antibacterial activity with its free carboxylic acid group (Niedermeyer et al. 2013). Al-Fatimi et al. (2016) obtained four volatile oil, 1-octen-3-ol (amyl vinyl carbinol), 1octen-3-ol acetate, phenylacetaldehyde and 6-camphenol from G. pfeifferi. They demonstrated the strong antimicrobial activity of the oil against $S$. aureus and Candida albicans. It was found that the Gram-positive bacteria species are more sensitive to the essential oil than Gram-negative bacteria. Furthermore, the oil exhibited strong radical scavenging activity in the DPPH assay.

\section{Ganoderma petchii and G. resinaceum}

Ganoderma petchii provided five new compounds, (-)-petchioics A and B, petchiates A and $\mathrm{B}$ and Petchine (5), and a known compound. The structures of the new compounds were elucidated on the basis of spectroscopic data. The absolute configurations of 1 and 2 were assigned by computational methods. Biological activities of these isolates towards human cancer cells, COX$1 / 2$, and influenza virus were evaluated. Five new compounds, Petchienes A-E, were isolated from the fruiting bodies of $G$. petchii. Biological evaluation showed that compounds Petchiene B and racemic Petchiene D could increase intracellular free calcium concentration at $10 \mu \mathrm{M}$ in HEK-293 cells (Gao et al. 2015). Ganoderma resinaceum tolerated sodium chloride ( $\mathrm{NaCl}$ ) salt stress within a range of $0 \mathrm{mM}$ till $300 \mathrm{mM}$. It responded to salt stress with fluctuation in Proline formation at different $\mathrm{NaCl}$ concentrations (Mahmoud et al. 2007). Ganoderol exhibited a vital activation for PXR-induced CYP3A4 expression. Thus it suggested Ganoderma triterpenoids exhibited hepatoprotective activities by lowering ALT and AST levels (Peng et al. 2013). Ganoderma praelongum was synonymized as $G$. resinaceum according to Index Fungorum.This species was evaluated against 30 strains of clinical isolatesof methicillin-resistant and -sensitive $S$. aureus. The ethyl acetate extract of this speciescontainingsesquiterpenoids exhibited the maximum activity $(35.67 \pm 0.62 \mu \mathrm{m})$ and minimum inhibitory concentration (MIC) of $0.390-6.25 \mathrm{mg} / \mathrm{mL}$ (Ameri et al. 2011). Coletto \& Mondino (1991) demonstrated methanolic extracts of the mycelia and culture extracts of G. resinaceum inhibited B. subtilis and Staphylococcus aureus. But Zengin et al. (2015) showed methanol and water extracts of $G$. resinaceum possess weak antibacterial and antifungal activities.

\section{Ganoderma sinense}

Both AFGS (artificial and fermentative G. sinense) and natural G. sinense (Fig. 1) (NGS) have obvious anti-inflammatory and analgesic effects for arthritis in rats induced by carrageenan and the pain reaction in mice induced by hot scalding as well as HAC-induced writhing. AFGS also can reduce the edematous swelling of mice's ears, reduce the capillary permeability of mice skin and obviously inhibit cotton pellets granuloma implanted in rats. It can promote cytophagy capacity 
of the reticular endothelial cells in mice (Wan \& Huang 1992). Triterpenoid-enriched lipids have emerged due to their immunomodulatory and cytotoxic effects. Dose-dependent suppression of proliferation of leukemia and hepatoblastoma cells has been described for a lipid extract of this $G$. sinense mushroom, known as GL6. Furthermore, the same GL6 was shown to induce human monocytes and immunosuppressive M2 macrophages to release pro-inflammatory cytokines (Yue et al. 2008).

Studies of Liu et al. (2009) concluded ethanol extracts of $G$. sinense responsible for activities on human breast cancer, hepatoma and myeloid leukemia, anti-proliferation effect through apoptosis pathway and cell cycle arrest effect. Ganoderma sinense have anti-tumoral proliferation effect through both apoptosis pathway and cell cycle arrest effect, and some other compounds such as sterols and/or nucleosides may contribute to their activity besides triterpenoids. Ganoderic acids GS-2 and 20(21)-dehydrolucidenic acid N, inhibited the human immunodeficiency virus-1 protease with IC values of 20 to $40 \mathrm{mM}$ (Sato et al. 2009a). The recombinant FIP-gsi protein could be expressed in E. coli and got the yield of about $25 \%$ of the soluble form in the total soluble protein. The FIP-gsi protein was composed of 111 amino acids, and the sequence of homologous rate was 88.6\% with FIP-glu (LZ-8). Furthermore, it could enhance the levels of interleukin (IL)-2, IL-3, IL4 , interferon gamma, tumor necrosis factor alpha, and IL-2 receptor (IL-2R) in mouse spleen cells (Li et al. 2010b).

A polysaccharide (GSP-6B) was isolated from the fruiting bodies of $G$. sinense. An in vitro immunomodulating activity assay revealed that GSP-6B could significantly induce the release of IL- $1 \beta$ and TNF- $\alpha$ in human peripheral blood mononuclear cell (PBMC) and showed no toxicity to either PBMC or a human macrophage cell line THP-1. GSP-6B could also activate dendritic cells (DC) by stimulating the secretion of IL-12 and IL-10 from DC (Han et al. 2012a). A protein-bound polysaccharide (GSP-4) was isolated from the water extract of the fruiting bodies of G. sinense. GSP-4 could significantly stimulate the production of the immunomodulatory markers tumor necrosis factor $\alpha$ (TNF- $\alpha$ ), interleukin (IL)-1 $\beta$, IL-12, and granulocyte-macrophage colonystimulating factor (GM-CSF) in PBMCs. This observation was further substantiated in RAW 264.7 cells, as indicated by the increase of nitric oxide (NO), TNF- $\alpha$ and IL-6 production. GSP-4 also enhanced the expression of inducible NO synthase mRNA in dose-dependent manner (Han et al. 2012b).

Ganoderic acid Jc displayed selective inhibitory activity against HL-60 and Ganoderiol E exhibited selective cytotoxic activity against MCF-7 cells. Meanwhile, Ganodermatetraol, Ganolucidate, and Ganolucidic acids B and C showed induction ability of hPXR-mediated CYP3A4 expression (Liu et al. 2012). Polysaccharide-enriched fraction of G. sinense hot water extract $(400 \mu \mathrm{g} / \mathrm{ml})$ exhibited significant stimulatory effects on PBMC proliferation. When the fruiting bodies of $G$. sinense were divided into pileus and stipe parts and were separately extracted, the $G$. sinense stipe polysaccharide-enriched fraction $(50-400 \mu \mathrm{g} / \mathrm{ml})$ showed concentrationdependent immunostimulating effects in human peripheral blood mononuclear cells (PBMC). The productions of tumor necrosis factor- $\alpha$, interleukin (IL)-10, and transforming growth factor $-\beta$ were significantly enhanced by this fraction. The proportion of CD14 (+) monocyte subpopulation within the PBMC was specifically increased. The IL-10 and IL-12 productions in monocyte-derived dendritic cells were significantly enhanced by $G$. sinense stipe fraction (Yue et al. 2013). The recombinant proteins FIP-SN15 and FIP-glu (reFIPs) on U-251 MG cell cycle indicated that reFIPs could inhibit cell cycle progression by retardation of G1/S transition. The efforts in this assay would lay the foundation for further development of reFIPs products and research on the anti-tumor mechanisms of FIP-SN15 (Cong et al. 2014).

A polysaccharide GSP-2 was isolated from the fruiting bodies of $G$. sinense. Immunological assay exhibited that GSP-2 significantly induced the proliferation of BALB/c mice splenocytes with target on only B cells, and enhanced the production of several cytokines in human peripheral blood mononuclear cells and derived dendritic cells (Han et al. 2014). Furthermore, they revealed FIP-gsi could enhance the production levels of cytokinine, including interleukin-2, 3 and 4 interferon gamma, TNF- $\alpha$, and interleukin receptor- 2 in mouse spleen cells. Four new farnesyl 
phenolic compounds, Ganosinensols A-D and two pairs of enantiomers were isolated from the $95 \%$ $\mathrm{EtOH}$ extract of the fruiting bodies of $G$. sinense. All of these isolated compounds showed potent inhibitory activity against LPS-induced nitric oxide production in RAW 264.7 macrophages (Wang et al. 2016a). Zizhines A-F, six pairs of new meroterpenoid enantiomers and a known meroterpenoid were isolated from the fruiting bodies of G. sinensis (Cao et al. 2016). (+)- and (-)Sinensilactam, novel hybrid metabolites were isolated from the fruit bodies of G. sinensis. (-)-1 Sinensilactam was found to be a Smad3 phosphorylation inhibitor in TGF- $\beta 1$ induced human renal proximal tubular cells (Luo et al. 2015). Chan et al. (2016) first reported the presence of 9- and 13oxo-octadecadienoic acids in the stipe of $G$. sinense and they might be responsible for the antitumor activities. Further studies will be needed to confirm their activities.

\section{Ganoderma tsugae}

Ganoderma tsugae is one of the popular traditional medicines used in China due to its various beneficial medicinal properties (Wasser \& Weis 1999). The fruiting bodies and cultured mycelia of $G$. tsugae have been reported to be effective in the treatment of many diseases, such as chronic hepatopathy, hypertension, and neoplasia (Kimura \& Tamura 1988, Lin et al. 1993). Splenic NK activity and serum IFN (IFN-(alpha+beta) and IFN-gamma) titers are elevated by G. tsugae mycelium extracts in mice (Won et al. 1992). Moreover, it has been reported many pharmacological properties, such as anti-autoantibody formation (Lai et al. 2001), anti-fibrosis (Wu et al. 2004), anti-inflammation (Ko et al. 2008), anti-oxidation characteristics (Mau et al. 2002) and anti-mutagenic activities (Zheng et al. 2005). Among the biologically active components, the polysaccharides, protein-bound polysaccharides and their derivatives have been demonstrated to be responsible for its antitumor activities, which are based on enhancing the host-mediated mechanism (Mizuno et al. 1985, Wang et al. 1993, Zhang et al. 1994, Gao et al. 2000, Seong 2000). This mushroom has growth-inhibitory effects in a variety of human cancer cells such as A431 epidermoid carcinoma cells (Hsu et al. 2009), COLO 205 colorectal cancer cells (Hsu et al. 2008), H23 and H23/0.3 lung adenocarcinoma cells (Yu et al. 2012b), Hep3B hepatoma cells (Gan et al. 1998a), MDA-MB-231 and MCF-7 breast cancercells (Yue et al. 2006). Crude extracts G. tsugae can be used as a treatment for the enhancement of splenic natural killer cell activity and serum interferon production in mice (Won et al. 1992). Mizuno (1995) extracted three antitumor-active polysaccharides from G. tsugae. They showed substantial survival ratio on Sarcoma 180/mice.

Gan et al. (1998a) found new lanostanoid ester glucoside, 3R-acetoxy-5R-lanosta-8, 24-dien-

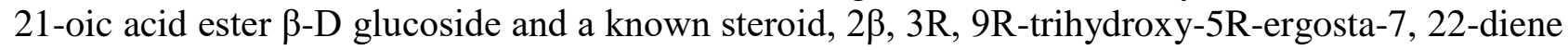
were isolated from the fruit bodies of $G$. tsugae. These two compounds are responsible for cell death by apoptosis and the activity of cell cycle inhibition respectively. Su et al. (1999) showed Sacchachitin membrane, prepared from the residue of the fruiting body of G. tsugae, was effective on wound healing and the proliferation and migration of fibroblast cells in female guinea pigs. The methanolic extract from G. tsugae, was found to be high in antioxidant abilities (Yen \& Wu 1999). The water-soluble polysaccharides of $G$. tsugae mycelium have bidirectional immunomodulatory effects on cytokine production in different stimulatory conditions in a dose-dependent manner. Compared with FI0-b, FI0-b-H has more marked effects on human proinflammatory cytokine production (Gao et al. 2000).

$\mathrm{Su}$ et al. (2000) examined the cytotoxic activity of lanostanoids from G. tsugae and found activity against three cancer cell lines. Kleinwächter et al. (2001) found Lucidenic acids and Colossolactones A inhibit HepG2 cancer cell invasion by acting as inhibitor on the phorbol-12myristate-13-acetate (PMA)-induced matrix metalloproteinase (MMP-9) expression. Ganoderma tsugae extracts improved the survival rate of lupus mice, decreased the amount of proteinuria, decreased serum levels of anti-dsDNA autoantibody, and showed evidence of decreased perivascular and parenchyma mononuclear cell infiltration in vital organs (Lai et al. 2001). Lin et al. (2003) demonstrated triterpenoids extracted from mycelia of $G$. tsugae caused a rapid decrease in the activity of cell growth regulative protein, PKC, and the activation of JNK and p38 MAP kinases, which resulted in a prolonged G2 cell cycle phase and strong growth inhibition of the 
hepatoma cells. Peng et al. (2003) obtained two novel heteropolysaccharides (EPF1 \& EPF2) from the crude extracellular polysaccharide of G. tsugae mycelium and the samples were exhibited high inhibition ratio against Sarcoma 180 in mice, and the crude extracellular polysaccharide has higher inhibition effect both in vivo and in vitro than heteropolysaccharides.

Peng \& Zhang (2003) extracted a novel water soluble polysaccharide-protein complex from the mycelium of G. tsugae. Methanolic, hot water and cold water extracts from G. tsugae possessed good antioxidant properties (Mau et al. 2005a, b, Tseng \& Mau 2007). Crude extracts of G. tsugae (GTE) has hepatoprotective and anti-fibrotic activities (Wu et al. 2004). Jinn et al. (2006) revealed, compared with the rFIP-gts produced in Escherichia coli cells, the rFIP-gts produced in Sf 21 cells possessed evidently higher specific immunomodulatory activity. Lin et al. (2006) reported a therapeutic application for $G$. tsugae in allergic asthma. Ganoderma tsugae supplementation in vivo modulated the Th1/Th2 balance and enhanced macrophage immune responses. However, the supplementation diet could not fully reverse the Th2-skewed responses to level of Th1-skewed responses. ReFIP-gts suppresses telomerase activity and inhibits transcriptional regulation of hTERT via a c-myc-responsive element-dependent mechanism (Liao et al. 2006). The nm23H1gene suppresses cervical cancer cell migration, activities of MMP-2 and MMP-9 and enhances the inhibition of FIP-gts upon migration (Wang et al. 2007). ReFIP-gts inhibits telomerase activity in lung cancer cells through nuclear export mechanisms, which might be mediated by Endoplasmic Reticulum stress-induced intracellular calcium level (Liao et al. 2007). Hsiao et al. (2008) introduces a FIP-gts immunomodulatory which having anti-cancer activities.

Hsu et al. (2008) studied the anti-tumour effects of $G$. tsugae extracts on colorectal adenocarcinoma cell proliferation. Tumorigenesis study in mice revealed the extracts caused tumor shrinkage. In vitro and in vivo experiments showed that colorectal adenocarcinoma cells are inhibited by induction of G2/M cell cycle arrest. Possibly through downregulation of cyclin A and $\mathrm{B} 1$ and up-regulation of $\mathrm{p} 21$ and $\mathrm{p} 27$. Also, no significant physiological changes as a result of treatment with $G$. tsugae extracts were observed in the animal model. Furthermore, Tseng et al. (2008) revealed hot water and hot alkali extracted polysaccharides from G. tsugae possessed good antioxidant properties except for scavenging ability on hydroxyl radicals. In addition to their therapeutic effects, G. tsugae could be used in human diets to suppress oxidative damage and hot water and hot alkaline extracted polysaccharides preparations could be developed as a new dietary supplementand functional food. Moreover, both extracted polysaccharidescould be added in emulsion to prevent anti-oxidation (Kishk \& Al-Sayed 2007) or formulated into bread as a healthpromoting functional food (Fan et al. 2007).

Ko et al. (2008) revealed tsugaric acid A isolated from G. tsugae exhibited significant inhibitory effects on fMLP/CB-induced superoxide anion generation and 3-oxo-5 $\alpha$-lanosta-8, 24dien-21-oic acid showed inhibitory effects on release of $\beta$-glucuronidase stimulated with fMLP/CB from rat neutrophils and accumulation of NO in the culture media of N9 cells in response to LPS/IFNc. The tsugaric acid A has a protective effect on keratinocytes against photodamage induced by ultraviolet B light and could be used as an agent for skin care. Liao et al. (2008) found that purified recombinant fungal immunomodulatory protein from Ganoderma tsugae (reFIP-gts) has anti-telomerase effects in human lung adenocarcinoma A549 cells. The reFIP-gts-treated lung cancer cells are arrested at G1 phase by flow cytometry and possess morphological phenotype consistent with cellular senescence. The A549 cells treated with reFIP-gts grew significantly slower than cells treated with PBS alone in an in vivo mouse model revealing that lung tumor can be inhibited by reFIP-gts. La Clair et al. (2011) reported the isolation and characterization of an unprecedented benzofuran, Ganodone from the fruiting bodies of mature G. tsugae. Ganoderma tsugae inhibits the viability of $\mathrm{H} 23 / 0.3$ cells in vitro and in vivo and sensitizes the growth suppression effect of doxorubicin on $\mathrm{H} 23 / 0.3$ cells and induces $\mathrm{S}$ phase arrest by interfering with the protein expression of cyclin A, cyclin E, CDK2, and CDC25A. Furthermore, GT induces cellular apoptosis via induction of a mitochondria/caspase pathway and suppression of cell proliferation by through down-regulation of the PI3K/Akt signaling pathway (Yu et al. 2012a). 
Kuo et al. (2013) revealed G. tsugae extract inhibits cancer cell growth and induces cell cycle arrest via modulation of the HER2/PI3K/Akt signaling pathway. Furthermore, combining G. tsugae extract with taxol or cisplatin significantly slows the growth of HER2-overexpressing cancer cells. Two new lanostanoids, Tsugaric acid D and Tsugaric acid E were isolated from the fruit bodies of G. tsugae and former compound with other two known compounds exhibited significant inhibitory effects on xanthine oxidase (XO) activity. Moreover, one known compound was able to protect human keratinocytes from photo damage and the other compound combined with cisplatin enhanced the cytotoxicity induced by cisplatin (Lin et al. 2013). Ganoderma tsugae possesses antiapoptotic and hepatoprotective potential after exhaustive exercise (Huang et al. 2013). Kuok et al. (2013) revealed that oral administration of $G$. tsugae can protect the mice from ISO-induced myocardial injury and the triterpenoid fraction of G. tsugae containing Ganoderic acids, provided cardio protection by inhibiting the ISO-induced expression of Fas/Fas ligand, oxidative stress, and apoptosis. Ganoderic acids dissipated the cellular reactive oxygen species imposed by $\mathrm{H}_{2} \mathrm{O}_{2}$ and prevented cell death. Lin et al. (2006) performed an experiment to show supplementation of $G$. tsugae significantly decreased total infiltrating leukocytes and lymphocyte percentage in BALF in the experimental groups. Supplementation of $G$. tsugae also significantly reduced inflammatory mediators in BALF including histamine, prostaglandin E2, and eotaxin. Ganoderma tsugae phosphorylates the human epidermal growth factor receptor 2 (HER2) which activates the variety of proteins such as PI3K/Akt and Ras/mitogenactivated protein kinase (MAPK) proteins in downstream signaling in cancer (Baselga \& Swain 2009). In vitro studies of G. tsugae indicated that administration of $G$. tsugae extract (GTE) induced G1 phase arrest via modulating cyclins D1, E, p21, and p27 in the cell cycle in ovarian cancer and breast cancer cells. Furthermore, G. tsugae arrests cyclin and cdks in HER2/ PI3K/Akt signaling which inhibit the growth of HER2 overexpressing cancer cells (Kuo et al. 2013).

Chiang et al. (2014) prepared nano/submicrometer particles from $G$. tsugae and both nano/submicrometer and hot-water extract G. tsugae exhibited no mutagenic potential to Salmonella typhimurium tester strains. Cell toxicity test also confirmed the safety of both nano/submicrometer and hot water extract G. tsugae. Li et al. (2014) reportedFIP-gts may have the potential to be utilized as a therapeutic adjuvant for the treatment of resistant urothelial cancer down-regulating Beclin-1 to activate autophagic cell death. Ganoderma tsugae exhibited antibacterial activity against $S$. aureus, B. subtilis and E. coli (Singdevsachan et al. 2015). DMSO extractof G. tsugae (GTDE) prevents particulate matter (PM) transmigration into the bloodstream, and the resultant dysfunction, by inhibiting oxidative stress production and endothelial permeability and thus decrease myocardial infarctions (Tseng et al. 2016). Lin et al. (2016) isolated anew lanostanoid, a novel palmitamide and three novel seco-lanostanoids and results indicated that some of the compounds may be used as cancer chemo preventive agents. Ganoderma tsugae ethyl acetate extract (GTEAE) showed high potential by inhibiting reporter activity. Results demonstrated that GTEAE had a strong effect on inhibitory protein $\kappa \mathrm{B} \alpha$ level in the higher concentration used (200 $\mathrm{gg} / \mathrm{mL}$ ), which could be compared with the effect of parthenolide. Furthermore, GTEAE demonstrated strong inhibition of I $\kappa \mathrm{B} \alpha$ phosphorylation (Chan et al. 2015). Hot water extracts, from immature G. tsugae, could be of used as an alternative cancer therapy since it has anti-proliferation effects on HL-60, Hep 3B, and C6 cells (Chien et al. 2015). Triterpenoids (Gt-TRE) and polysaccharide (Gt-PS) extracts from $G$. tsugae shows anti-allergic effects. Gt-TRE significantly suppressed histamine secreted from activated RBL-2H3 mast cells and interleukin- (IL-) 4 secreted from activated EL4 cells but not Gt-PS (Chen et al. 2015). Moreover, triterpenoids fraction of $G$. tsugae might be the main constituents to alleviate allergic asthma.

\section{Ganoderma tuberculosum, G. theaecola and G. tropicum}

Welti et al. (2010) reported the isolation of Ganoderic acid FWI from G. tuberculosum and its extracts might inhibit the growth of cancer cells however, it has been isolated only from $G$. tuberculosum, Ganoderic acid FWI might be used also as a chemotaxonomic marker. Ganoderic acid XL1, Ganoderenic acid AM1, Ganoderesin C and three other known triterpenoids isolated by 
G. theaecola exhibited hepatoprotective activities against DL-galactosamine-induced cell damage in HL-7702 cells (Liu et al. 2014).

The 3 $\beta, 7 \beta, 15 \beta$-trihydroxy-11, 23-dioxo-lanost-8, 16-dien-26-oic acid methyl ester extracted from G. tropicum (Fig. 3) exhibited definite inhibitory activity against AChE (Hu et al. 2013).

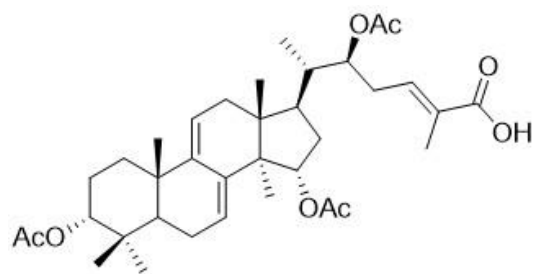

Ganoderic acid T

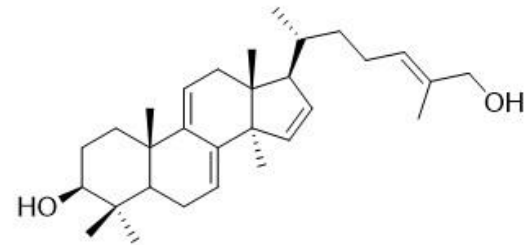

Ganoderol B

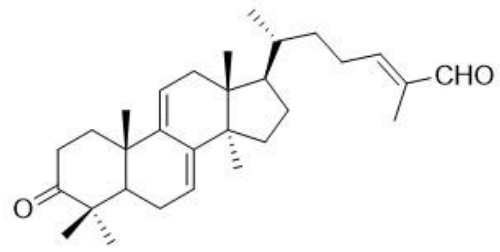

Ganoderal A

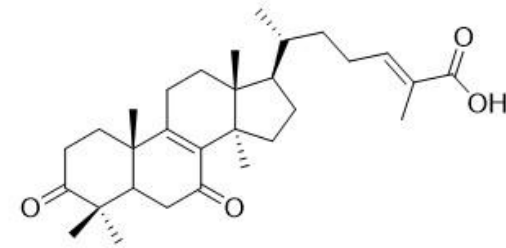

Ganoderic acid DM

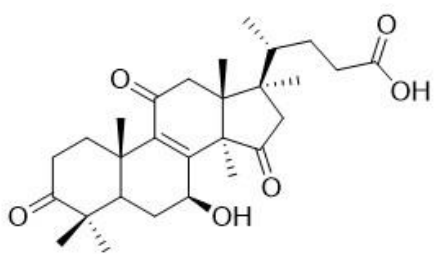

Lucidenic acid A

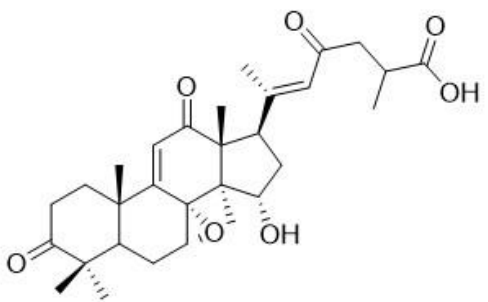

Applanoxidic acid A

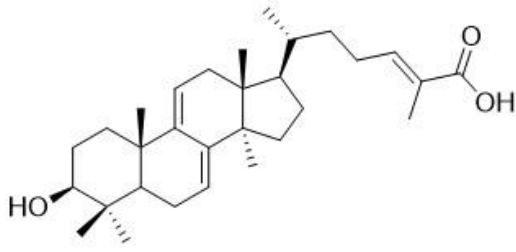

Ganoderic acid Y

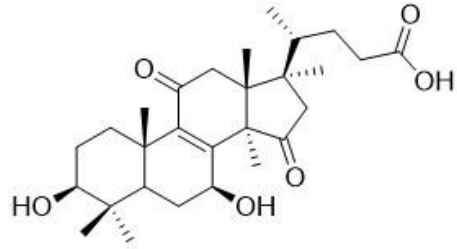

Lucidenic acid N

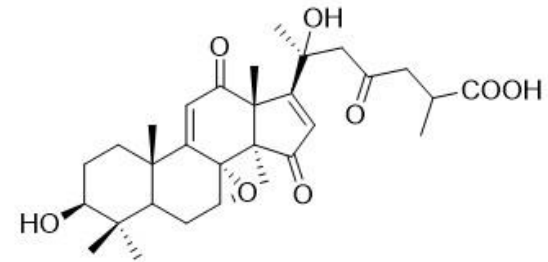

Applanoxidic acid D

Figure 4 - Typical Chemical structures of common compounds found within Ganoderma spp. (Hapuarachchi et al. 2016a).

\section{Ganoderma weberianum and G. zonatum}

Ganoderma weberianum, a tropical white-rot fungus with great economic and environmental importance, has been used as a traditional Chinese medicine with anticancer and antivirus properties (Gao \& Zhou 2003). Ganoderma weberianum TZC-1 was able to produce a high yield of laccase, which exhibited the strong ability to decolorize different dyes (Chen et al. 2010a,b). Mycelia pellets could also decolorize indigo carmine, indigo dye, and its effluents efficiently (Zhou et al. 2011b, Tian et al. 2013). Zhou et al. (2015b) established a simple and efficient genetic transformation method of G. weberianum via ATMT. This method included the growing mycelia of the fungus, Agrobactrium tumefaciensstrain GV3101, vector pBIH1 harboring the cauliflower mosaic virus (CaMV) 35S promoter and the selective hpt marker. The hygromycin phosphotransferase (hpt), $\beta$-glucuronidase (uidA), and enhanced green fluorescent protein (egfp) genes have been efficiently expressed in transgenic mycelia and spores of $G$. weberianum through co-cultivation of Agrobacterium lawn and fungal mycelia at $28{ }^{\circ} \mathrm{C}$ on yeast extract agar medium. Kinge \& Mih (2011) demonstrated the cytotoxicity of three lanostane-type triterpenoids, Lanosta-7, 9(11), 24-trien-3-one15, 26-dihydroxy, Lanosta-7, 9(11), 24-trien-26-oic, 3-hydroxy and Ganoderic acid Y (Fig. 4), isolated from fruiting bodies of G. zonatum, against five human tumor cell lines. 


\section{Discussion}

\section{Are the beneficial medicinal properties of Ganoderma truly substantiated?}

Ganoderma is now becoming accepted as a natural supplement to enhance the healing effects by supporting the immune system in combination with other therapies. Large number of scientific articles and patents from Ganoderma originate from research laboratories of Asian countries, such as Japan, China, and Korea. Recent in vitro and in vivo studies demonstrate the beneficial effects of species on various diseases. But, very few studies have been conducted with Ganoderma in human patients owing to poor methodological quality of these trials. In more recent studies, purified substances isolated from Ganoderma have been investigated to reveal the molecular mechanisms responsible for the antitumor and immunosupportive activities. One of the primary reactions of radiation and chemotherapy in the treatment of disease patients is the advancement of leukopenia, which fundamentally expands the danger of contaminations. Consequently, a few late reviews have looked into whether Ganoderma mushroom concentrates or constituents can upgrade hematopoiesis by investigating ideal dosing, viability and security, alone or in blend with chemotherapy or radiotherapy (Ulbricht et al. 2010).

In spite of the fact that recent studies focusing on molecular targets of chemical compunds yielded promising results, details of the disease mechanisms involved and the active components of Ganoderma extracts need to be further characterised. Besides, preclinical or clinical invistigations must be carried out to determine the potential of these compounds in disease prevention or therapy. Systematic, standardized research and the utilization of FDA administrative conventions and defined clinical trials are are still very constrained and should be effectively sought after. In the mean time, it is vital to researchers to effectively consider how to make novel, enhanced, or modified clinical surveys, studies, and trial mechanisms. More consideration needs to be paid to proper explanation of clinical results, which are of significance to patient care and clinical basic leadership including survival times, extent of relapse and quality of life. Utilizing dietary supplements from Ganoderma for specific diseases should be done with caution.

It has been reported that the concentration and composition of active ingredients of Ganoderma depends on upon a number of factors, e.g. the harvesting techniques, strains, cultivating areas, age, manipulation, and storage of the mushrooms and spores which in turn largely influence biological activities (Hattori 2001). Hence, it is largely recommended to take these into account whenever any of these chemical compounds are being extracted for medicinal purposes. Submerged liquid or solid state biotechnological processes in bioreactors under controlled conditions offer a quicker alternative for the production and isolation of Ganoderma pharmaceutically active substances (Zhou et al. 2011a). Many authors have postulated that Ganoderma preparations induce many biological activities in vitro and in vivo on animal models. However, potential promising findings, their efficacy and safety have not yet been supported by any single human clinical evidence up to now. Further research, scientific support and a deeper scientific understanding of the mechanisms are needed to confirm these effects. Hence well designed in vivo tests and randomized controlled clinical studies with Ganoderma can provide statistically significant results to confirm the efficacy and safety of Ganoderma applications. Further, standardization and quality control of Ganoderma species, cultivation processes, extracts and commercial formulations, are needed to accept these speciesas natural product for potential use in the prevention and treatment of various diseases.

\section{Conclusion}

Ganoderma has been used as a food supplement to prevent and treat many immunological diseases over the last 30 years. Some in vitro and in vivo studies of medicinal properties of Ganoderma appear to be promising, but careful investigation and accurate scientific evidences needed for establishing the safe and efficient use of Ganoderma. Experimental, epidemiological, and clinical studies should be carried out on identification of the molecular targets and investigate the association between Ganoderma intake and disease risk. Moreover, the efficacy dosage, 
efficacy of the drug, and safety, alone or in combination with chemotherapy or radiotherapy should also be researched in the future.

\section{Acknowledgements}

This work was financed by the the Science and Technology Foundation of Guizhou Province ((No. [2017]2511-1), China. Kalani K. Hapuarachchi is greatefull to Dr. Naritsada Thongklang and Ishani D. Goonasekara for their valuble comments and suggestions. The University of Mauritius is acknowleged for providing Dr R. Jeewon with appropriate support.

\section{References}

Acharya K, Yonzone P, Rai M, Acharya R. 2005 - Antioxidant and nitric oxide synthase activation properties of Ganoderma applanatum. Indian Journal of Experimental Biolology 43, 926929.

Akar T, Cabuk A, Tunali S, Yamac M. 2006 - Biosorption potential of the macro fungus Ganoderma carnosum for removal of lead (II) ions from aqueous solutions. Journal of Environmental Science and Health, Part A 41, 2587-2606.

Al-Fatimi M, Wurster M, Lindequist U. 2016 - Chemical composition, antimicrobial and antioxidant activities of the volatile oil of Ganoderma pfeifferi Bres. Medicines 3, 10.

Al-Fatimi M. 2001 - Isolierung und Charakterisierung antibiotisch wirksamer Verbindungen aus Ganoderma pfeifferi Bres.und aus Podaxis pistillaris (L.: Pers.) Morse. Ph.D. Thesis, University of Greifswald, Greifswald, Germany (in German).

Amen Y, Zhu Q, Tran HB, Afifi MS et al. 2017 - Partial contribution of Rho-kinase inhibition to the bioactivity of Ganoderma lingzhi and its isolated compounds: insights on discovery of natural Rho-kinase inhibitors. Journal of Natural Medicines 1-9.

Amen YM, Zhu Q, Tran HB. 2016 - Lucidumol C, a new cytotoxic lanostanoid triterpene from Ganoderma lingzhi against human cancer cells. Journal of Natural Medicines 70, 661-666.

Ameri A, Vaidya JG, Deokule SS. 2011 - In vitro evaluation of anti-staphylococcal activity of Ganoderma lucidum, Ganoderma praelongum and Ganoderma resinaceum from Pune, India. African Journal of Microbiology Research 5, 328-333.

Baby S, Johnson AJ, Govindan B. 2015 - Secondary metabolites from Ganoderma. Phytochemistry $114,66-101$.

Baselga J, Swain SM. 2009 - Novel anti-cancer targets: revisiting ERBB2 and discovering ERBB3. Nature Reviews, Cancer 9, 463-475.

Bhattacharyya C, De S, Basak A, Banerjee M et al. 2006 - Antimicrobial activities of some basidiomycetous fungi. Journal of Mycopathological Research 44, 129-135.

Bishop KS, Kao CHJ, Xu Y, Glucina MP et al. 2015 - From 2000 years of Ganoderma lucidum to recent developments in nutraceuticals. Phytochemistry 114, 56-65.

Boh B, Hodzar D, Dolnicar D, Berovic M et al. 2000 - Triterpenoid acids from Ganoderma applanatum. Food technology and Biotechnology 38, 11-18.

Cao WW, Luo Q, Cheng YX, Wang SM. 2016 - Meroterpenoid enantiomers from Ganoderma sinensis. Fitoterapia 110-115.

Cao Y, Yuan HS. 2013 - Ganoderma mutabile sp. nov. from Southwestern China based on morphological and molecular data. Mycological Progress 12, 121-126.

Chairul SM, Hayashi Y. 1994 - Lanostanoid triterpenes from Ganoderma applanatum. Phytochemistry 35, 1305-1308.

Chairul TT, Nishizawa M, Shiro M, Tokuda H et al. 1990 - Malonate half-esters of homolanostanoid from an Asian Ganoderma fungus. Phytochemistry 29, 923-928.

Chan JS, Asatiani MD, Sharvit LE, Trabelcy B et al. 2015 - Chemical composition and medicinal value of the new Ganoderma tsugae var. jannieae CBS-120304 medicinal higher basidiomycete mushroom. International Journal of Medicinal Mushrooms 17, 735-747. 
Chan KM, Yue GGL, Li P, Wong ECW et al. 2016 - Identification of potential anti-tumor compounds from the stipe of Ganoderma sinense using liquid chromatography-mass spectrometry-based chemometrics. Planta Medica 81, 89

Chen DH, Chen WKD. 2003 - Determination of Ganoderic acids in triterpenoid constituents of Ganoderma tsugae. Journal of Food and Drug Analysis 195-201.

Chen QH, Zhou YP, Chen X, Ke DS et al. 2010a - Purification and characterization of laccase from Ganoderma weberianum. Food Science 31, 201-205.

Chen QH, Zhou YP, Jiang GJ, Li GY et al. 2010b - Laccase production by Ganoderma weberianum fermentation and its decolorization effect on Indigo dye. Food and Fermentation Industries 36, 25-30.

Chen Y, Xie MY, Gong XF. 2007 - Microwave-assisted extraction used for the isolation of total triterpenoid saponins from Ganoderma atrum. Journal of Food Engineering 81, 162-170.

Chen Y, Zhang H, Wang YX, Nie SP et al. 2014 - Acetylation and Carboxymethylation of the polysaccharide from Ganoderma atrum and their antioxidant and immunomodulating activities. Food Chemistry 156, 279-288.

Chen Y, Zhang H, Wang YX, Nie SP et al. 2015 - Sulfated modification of the polysaccharides from Ganoderma atrum and their antioxidant and immunomodulating activities. Food Chemistry 1, 231-238.

Cheng CR, Li YF, Xu PP, Feng RH et al. 2012a - Preparative isolation of triterpenoids from Ganoderma lucidum by counter current chromatography combined with $\mathrm{pH}$-zone-refining. Food Chemistry 130, 1010-1016.

Cheng CR, Yang M, Guan SH, Wu XH et al. 2013a - Pharmacokinetics of ganoderic acid D and its main metabolite by liquid chromatography-tandem mass spectrometry. Journal of Chromatography B-Analytical Technologies in the Biomedical and Life Sciences 930, 1-6.

Cheng CR, Yang M, Wu ZY, Wang Y et al. 2011 - Fragmentation pathways of oxygenated tetracyclic triterpenoids and their application in the qualitative analysis of Ganoderma lucidum by multistage tandem mass spectrometry. Rapid Communications in Mass Spectrometry 25, 1323-1335.

Cheng CR, Yang M, Yu K, Guan SH et al. 2012b - Metabolites identification of ganoderic acid D by ultraperformance liquid chromatography/quadrupole time-of-flight mass spectrometry. Drug Metabolism and Disposition 40, 2307-2314.

Cheng CR, Yang M, Yu K, Guan SH et al. 2013b - Metabolite identification of crude extract from Ganoderma lucidum in rats using ultra-performance liquid chromatography-quadrupole timeof-flight mass spectrometry. Journal of Chromatography B-Analytical Technologies in the Biomedical and Life Sciences 941, 90-99.

Cheng CR, Yue QX, Wu ZY, Song XY et al. 2010 - Cytotoxic triterpenoids from Ganoderma lucidum. Phytochemistry 71, 1579-1585.

Chiang YH, Chen SH, Yeh AI. 2014 - Preparation of Nano/Submicrometer Ganoderma tsugae and its mutagenic potencies and cytotoxicity. Journal of Agricultural and Food Chemistry 62, 12244-12255.

Chien RC, Yen MT, Tseng YH, Mau JL. 2015 - Chemical characteristics and anti-proliferation activities of Ganoderma tsugae polysaccharides. Carbohydrate Polymers 128, 90-98.

Chiu LY, Hu ME, Yang TY, Hsin IL et al. 2015 - Immunomodulatory protein from Ganoderma microsporum induces pro-death autophagy through Akt-mTOR-p70S6K pathway inhibition in multidrug resistant lung cancer cells. PLoS ONE 10, e0125774.

Choon RLT, Sariah M, Mariam MNS. 2011 - Ergosterol from the soil borne fungus Ganoderma boninense. Journal of Basic Microbiology 52, 608-612.

Cole RJ, Schweikert MA. $2003-\mathrm{C}_{28}$ Sterols. In: Cole RJ, Jarvis BB, Schweikert MA. (Eds) Handbook of Secondary Fungal Metabolites 2, Elsevier 27-90.

Coletto BMA, Mondino P. 1991 - Antibiotic activity in Basidiomycetes: V. Antibiotic activity of mycelia and cultural filtrates. Allionia (Turin) 30, 61-64. 
Cong WR, Xu H, Liu Y, Li QZ et al. 2014 - Production and functional characterization of a novel fungal immunomodulatory protein FIP-SN shuffled from two genes of Ganoderma species. Applied Microbiology and Biotechnology 98, 5967-5975.

Dai YC, Yang ZL, Cui BK, Yu CJ et al. 2009 - Species diversity and utilization of medicinal mushrooms and fungi in China (Review). International Journal of Medicinal Mushrooms 11, 287-302.

De Melo RH, do Amaral AE, Menolli RA, Ayala TS et al. $2016-\beta-(1 \rightarrow 3)$-Glucan of the Southern Bracket Mushroom, Ganoderma australe (Agaricomycetes), Stimulates Phagocytosis and Interleukin-6 Production in Mouse Peritoneal Macrophages. International Journal of Medicinal Mushrooms 18.

De Silva DD, Rapior S, Fons F, Bahkali AH et al. 2012a - Medicinal mushrooms in supportive cancer therapies: an approach to anti-cancer effects and putative mechanisms of action. Fungal Diversity 55, 1-35.

De Silva DD, Rapior S, Hyde KD, Bahkali AH. 2012b - Medicinal mushrooms in prevention and control of diabetes mellitus. Fungal Diversity 56, 1-29.

De Silva DD, Rapior S, Sudarman E, Stadler M et al. 2013 - Bioactive metabolites from macrofungi: ethnopharmacology, biological activities and chemistry. Fungal Diversity 62, 140.

De Silva ED, Van der sar SA, Santha RGL, Wijesundara RLC et al. 2006 - Lanostane triterpenoids from the Sri Lankan Basdiomycete Ganoderma applanatum. Journal of Natural Products 69, $1245-1248$.

Donk MA. 1948 - Notes on Malaysian fungi. I Bulletin du Jardin botanique de Buitenzorg 17, 473-482.

Dou M, Di L, Zhou LL, Yan YM et al. 2014 - Cochlearols A and B, Polycyclic Meroterpenoids from the fungus Ganoderma cochlear that have renoprotective activities. Organic letters 16, 6064-6067.

El Dine RS, El Halawany AM, Ma C-M, Hattori M. 2008 - Anti-HIV-1 protease activity of lanostane triterpenes from the Vietnamese mushroom Ganoderma colossum. Journal of Natural Products 71, 1022-1026.

El Dine RS, El Halawany AM, Ma CM, Hattori M. 2009 - Inhibition of the dimerization and active site of HIV-1 protease by secondary metabolites from the Vietnamese mushroom Ganoderma colossum. Journal of Natural Products 72, 2019-2023.

Elissetche JP, Ferret A, Freer J, Rodríguez J. 2007 - Enzymes produced by Ganoderma australe growing on wood and in submerged cultures. World Journal of Micrbiology and Biotechnology 23, 429-434.

Fan L, Zhang S, Yu L, Ma L. 2007 - Evaluation of antioxidant property and quality of breads containing Auricularia auricula polysaccharide flour. Food Chemistry 101, 1158-1163.

Fatmawati S, Kondo R, Shimizu K. 2013 - Structure-activity relationships of lanostane-type triterpenoids from Ganoderma lingzhi as alpha-glucosidase inhibitors. Bioorganic \& Medicinal Chemistry Letters 23, 5900-5903.

Fushimi K, Horikawa M, Suzuki K, Sekiya A et al. 2010 - Applanatines A to E from the culture broth of Ganoderma applanatum. Tetrahedron 66, 9332-9335.

Gan KH, Fann YF, Hsu SH, Kuo KW et al. 1998a - Mediation of the cytotoxicity of lanostanoids and steroids of Ganoderma tsugae through apoptosis and cell cycle. Journal of Natural Products 61, 485-487.

Gan KH, Kuo SH, Lin CN. 1998b - Steroidal constituents of Ganoderma applanatum and Ganoderma neo-japonicum. Journal of Natural Products 61, 1421-1422.

Gao QL, Guo PX, Luo Q, Yan H et al. 2015 - Petchienes A-E, Meroterpenoids from Ganoderma petchii. Natural Product Communications 10, 2019-2022.

Gao XX, Fei XF, Wang BX, Zhang J et al. 2000 - Effects of polysaccharides (FI0-b) from mycelium of Ganoderma tsugae on pro inflammatory cytokine production by THP-1 cells and human PBMC (I). Acta Pharmacologica Sinica 21, 1179-1185. 
Gao YH, Zhou SF. 2003 - Cancer prevention and treatment by Ganoderma, a mushroom with medicinal properties. Food Reviews International 19, 275-325.

Global mushroom business platform (CEMBN) (www.cembn.com). [accessed 22 February 2017].

Gonzalez AG, Leon F, Rivera A, Padran JI et al. 2002 - New lanostanoids from the fungus Ganoderma concinna. Journal of Natural Products 65, 417-421.

Han XQ, Chan BC, Yu H, Yang YH et al. 2012a - Structure characterization, and immunomodulating activity of a hyperbranched polysaccharide from the fruiting bodies of Ganoderma sinense. Journal of Agricultural and Food Chemistry 60, 4276-4281.

Han XQ, Chan BCL, Yu H, Yang YH et al. 2012b - Structural characterization and immunomodulating activities of a polysaccharide from Ganoderma sinense. International Journal of Biological Macromolecules 51, 597-603.

Han XQ, Yue GL, Yue RQ, Dong CX et al. 2014 - Structure Elucidation and Immunomodulatory Activity of A Beta Glucan from the Fruiting Bodies of Ganoderma sinense. PLoS ONE 9, e100380.

Hapuarachchi KK, Wen TC, Deng CY, Kang JC et al. 2015 - Mycosphere Essays 1: Taxonomic confusion in the Ganoderma lucidum species complex. Mycosphere 6, 542-559.

Hapuarachchi KK, Wen TC, Jeewon R, Wu XL et al. 2016a - Mycosphere Essays 7: Ganoderma lucidum - are the beneficial anti-cancer properties substantiated? Mycosphere 7, 305-332.

Hapuarachchi KK, Wen TC, Jeewon R, Wu XL et al. 2016b - Mycosphere Essays 15. Ganoderma lucidum - are the beneficial medical properties substantiated? Mycosphere 7, 687-715.

Hattori M. 2001 - Recent studies on the bitter principles of Ganoderma lucidum - isolation of novel triterpenes, their biological activity and pharmacokinetics. In: Proceedings of International Symposium on Ganoderma Science.

Hirotani M, Ino C, Hatano A, Takayanagi H et al. 1995 - Ganomastenols A, B, C and D, cadinene sesquiterpenes, from Ganoderma mastoporum. Phytochemistry 40, 161-165.

Hsiao YM, Huang YL, Tang SC, Shieh GJ et al. 2008 - Effect of a fungal immunomodulatory protein from Ganoderma tsugae on cell cycle and interferon-gamma production through phosphatidylinositol 3-kinase signal pathway. Process Biochemistry 43, 423-430.

Hsin IL, Ou CC, Wu MF, Jan MS et al. 2015 - GMI, an Immunomodulatory Protein from Ganoderma microsporum, Potentiates Cisplatin-Induced Apoptosis via Autophagy in Lung Cancer Cells. Molecular Pharmaceutics 12, 1534-1543.

Hsin IL, Ou CC, Wu TC, Jan MS et al. 2011 - GMI, an immunomodulatory protein from Ganoderma microsporum, induces autophagy in non-small cell lung cancer cells. Autophagy 7, 873-882.

Hsin IL, Sheu GT, Jan MS, Sun HL et al. 2012 - Inhibition of lysosome degradation on autophagosome formation and responses to GMI, an immunomodulatory protein from Ganoderma microsporum. British Journal of Pharmacology 167, 1287-1300.

Hsu CC, Lin KY, Wang ZH, Lin WL et al. 2008 - Preventive effect of Ganoderma amboinense on acetaminophen-induced acute liver injury. Phytomedicine 15, 946-950.

Hsu SH, Ou CC, Chuang TC, Li JW et al. 2009 - Ganoderma tsugae extract inhibits expression of epidermal growth factor receptor and angiogenesis in human epidermoid carcinoma cells: In vitro and in vivo. Cancer Letters 281, 108-116.

Hu LL, Ma QY, Huang SZ, Guo ZK et al. 2013 - Three New Lanostanoid Triterpenes from the Fruiting Bodies of Ganoderma tropicum. Journal of Asian Natural Products Research 15, 357-362.

Hu LL, Ma QY, Huang SZ, Guo ZK et al. 2014 - A new nortriterpenoid from the fruiting bodies of Ganoderma tropicum. Phytochemistry Letters 7, 11-13.

Huang CC, Huang WC, Yang SC, Chan CC et al. 2013 - Ganoderma tsugae Hepatoprotection against Exhaustive Exercise-Induced Liver Injury in Rats. Molecules 18, 1741-1754.

Huang J, Nie Q, Liu X, Zhang S et al. 2016a - Ganoderma atrum polysaccharide modulates TNF- $\alpha$ secretion and mRNA expression in macrophages of S-180 tumor-bearing mice. Food Hydrocolloids 53, 24-30. 
Huang SZ, Cheng BH, Ma QY, Wang Q et al. 2016b - Anti-allergic prenylated hydroquinones and alkaloids from the fruiting body of Ganoderma calidophilum. RSC Advances 6, 21139-2114.

Huang Y, Li N, Wand JB, Zhang D et al. 2015 - Structural characterization and antioxidant activity of a novel heteropolysaccharide from the submerged fermentation mycelia of Ganoderma capense. Carbohydrate Polymers 134, 752-760.

Huie CW, Di X. 2004 - Chromatographic and electrophoretic methods for Lingzhi pharmacologically active components. Journal of Chromatography B 812, 241-257.

Index Fungorum (2017) http://www.indexfungorum.org [accessed 22 February 2017].

Isaka M, Chinthanom P, Kongthong S, Srichomthong K et al. 2013 - Lanostane triterpenes from cultures of the basidiomycete Ganoderma orbiforme BCC 22324. Phytochemistry 87, $133-$ 139.

Jain AC, Gupta SK. 1984 - The isolation of lanosta-7, 9 (11), 24-trien- 3b, 21-diol from the fungus Ganoderma australe. Phytochemistry 23, 686-687.

Jeong S, Rebeiz M, Andolfatto P, Werner T et al. 2008 - The evolution of gene regulation underlies a morphological difference between two Drosophila sister species. Cell 132, $783-$ 793.

Jiang J, Kong F, Li N, Zhang D et al. 2016 - Purification, structural characterization and in vitro antioxidant activity of a novel polysaccharide from Boshuzhi. Carbohydrate Polymers 147, 365-371.

Jiao Y, Xie T, Zou LH, Wei Q et al. 2016 - Lanostane triterpenoids from Ganoderma curtisii and their NO production inhibitory activities of LPS-induced microglia. Bioorganic \& Medicinal Chemistry Letters 26, 3556-3561.

Jinn TR, Wu CM, Tu WC, Ko JL et al. 2006 - Functional expression of FIP-gts, a fungal immunomodulatory protein from Ganoderma tsugae in Sf21 insect cells. Bioscience, Biotechnology, and Biochemistry 70, 2627-2634.

Jo WS, Park HN, Cho DH, Yoo YB et al. 2011a - Detection of extracellular enzyme activities in Ganoderma neo-japonicum. Mycobiology 39, 118-120.

Jo WS, Park HN, Cho DH, Yoo YB et al. 2011b - Optimal Media Conditions for the Detection of Extracellular Cellulase Activity in Ganoderma neo-japonicum. Mycobiology 39, 129-132.

Jonathan SG, Kigigha LT, Ohimain E. 2008 - Evaluation of the Inhibitory Potentials of Eight higher Nigerian Fungi against Pathogenic microorganisms. African Journal of Biomedical Research 11, 197-202.

Jong SC, Birmingham JM. 1991 - Medicinal benefit of the mushroom Ganoderma. Advances in Applied Microbiology 37, 104-132.

Jung SH, Lee YS, Shim SH, Lee S et al. 2005 - Inhibitory effects ofGanoderma applanatumon rat lens aldose reductase and sorbitol accumulation in streptozotocin-induced diabetic rat tissues. Phytotherapy Research 19, 477-480.

Jung M, Johannes C, Liermann JC, Opatz T et al. 2011 - Ganodermycin, a novel inhibitor of CXCL10 expression from Ganoderma applanatum. The Journal of Antibiotics 64, 683-686.

Karsten PA. 1881 - Enumeralio boletinearum et polypore arum fennicarum, systemate novo dispositarum. Revue Mycologie 3, 16-19.

Keller AC, Keller J, Maillard MP, Hostettmann K. 1997 - A lanostane-type steroid from the fungus Ganoderma carnosum. Phytochemistry 46, 963-965.

Kim SH, Song YS, Kim SK, Kim BC et al. 2014 - Anti-inflammatory and related Pharmacological activities of the n-BuOH subfraction of mushroom Phellinus linteus. Journal of Ethnopharmacology 93, 141-146.

Kimura S, Tamura T. 1988 -Dietary effect of Ganoderma lucidum mushroom on blood pressure and lipid levels in spontaneously hypertensive rats (SHR). Journal of Nutritional Science and Vitaminology 34, 433-438.

Kinge TR, Mih AH. 2011 - Secondary metabolites of oil palm isolates of Ganoderma zonatum Murill. from Cameroon and their cytotoxicity against five human tumor cell lines. African Journal of Biotechnology 10, 8440-8447. 
Kinge TR, Mih AH. 2014 - Ganoderma Lobenense (Basidiomycetes), a New Species from Oil Palm (Elaeis Guineensis) in Cameroon. Journal of Plant Sciences 2, 242-245.

Kishk YFM, Al-Sayed HM. 2007 - Free-radical scavenging and anti-oxidative activities of some polysaccharides in emulsions. LWT - Food Sciences and Technology 40, 270-277.

Kleinwächter P, Anh N, Kiet TT, Schlegel B et al. 2001 - Colossolactones, new triterpene metabolites from a Vietnamese mushroom Ganoderma colossum. Journal of Natural Products 64, 236-239.

Ko HH, Hung CF, Wang JP, Lin CN. 2008 - Anti-inflammatory triterpenoids and steroids from Ganoderma lucidum and G. tsugae. Phytochemistry 69, 234-249.

Komoda Y, Shimizu M, Sonoda Y, Sato Y. 1989 - Ganoderic acid and its derivatives as Cholesterol synthesis inhibitors. Chemical and Pharmaceutical Bulletin 37, 531-533.

Kuo HP, Hsu SC, Ou CC, Li JW et al. 2013 - Ganoderma tsugae Extract Inhibits Growth of HER2-Overexpressing Cancer Cells via Modulation of HER2/PI3K/Akt Signaling Pathway. Evidence-based Complementary and Alternative medicine 2013. doi: http://dx.doi.org/10.1155/2013/219472.

Kuok QY, Yeh CY, Su BC, Hsu PL et al. 2013 - The triterpenoids of Ganoderma tsugae prevent stress-induced myocardial injury in mice. Molecular Nutrition \& Food Research 57.

La Clair J, Rheingold R, Burkart MD. 2011 - Ganodone, a Bioactive Benzofuran from the Fruiting Bodies of Ganoderma tsugae. Journal of Natural Products 74, 2045-2051.

Lai NS, Lin RH, Lai RS, Kun UC et al. 2001 - Prevention of autoantibody formation and prolonged survival in New Zealand Black/New Zealand White F1 mice with an ancient Chinese herb, Ganoderma tsugae. Lupus 10, 461-465.

Lanfermann I, Linke D, Nimtz M. 2015 - Manganese Peroxidases from Ganoderma applanatum Degrade $\beta$-Carotene under Alkaline Conditions. Applied Biochemistry and Biotechnology $175,3800-3812$.

Lee IS, Ahn BR, Choi JS, Hattori M et al. 2011 - Selective cholinesterase inhibition by lanostane triterpenes from fruiting bodies of Ganoderma lucidum. Bioorganic \& Medicinal Chemistry Letters 21, 6603-6607.

Lee S, Shim SH, Kim JS, Shin KH et al. 2005 - Aldose reductase inhibitors from the fruiting bodies of Ganoderma applanatum. Biological and Pharmaceutical Bulletin 28, 1103-1105.

Lee SH, Shim SH, Kim JS, Kang SS. 2006 - Constituents from the fruiting bodies ofGanoderma applanatumand their aldose reductase inhibitory activity. Archives of Pharmacal Research 29, 479-483.

Lee WY, Park EJ, Ahn JK, Ka KH. 2009 - Ergothioneine Contents in Fruiting Bodies and Their Enhancement in Mycelial Cultures by the Addition of Methionine. Mycobiology 37, 43-47.

Lee WY, Park Y, Ahn JK, Ka KH et al. 2007 - Factors influencing the production of endopolysaccharide and exopolysaccharide from Ganoderma applanatum. Enzyme and Microbial Technology 40, 249-254.

León F, Valencia M, Rivera A, Nieto I et al. 2003 - Novel cytostatic lanostanoid triterpenoids from Ganoderma australe. Helvetica Chimica Acta 86, 3088-3095.

Li CH, Chen PY, Chang UM, Kan LS et al. 2005 - Ganoderic acid X, a lanostanoid triterpene, inhibits topoisomerases and induces apoptosis of cancer cells. Life Sciences 77, 252-265.

Li J, Zhang J, Chen H, Chen X et al. 2013 - Complete mitochondrial genome of the medicinal mushroom Ganoderma lucidum. PLoS One 8, e72038.

Li JR, Cheng CL, Yang WJ, Yang CR et al. 2014 - FIP-gts potentiate autophagic cell death against cisplatin-resistant urothelial cancer cells. Anticancer Research 34, 2973-2983.

Li L, Li H, Peng XR, Hou B et al. 2016a - Ganoapplanin, a pair of polycyclic meroterpenoid enantiomers from Ganoderma applanatum. Organic Letters 18, 6078-6081.

Li Q, Wang X, Chen Y. 2010b - Cytokines Expression Induced by Ganoderma sinensis Fungal Immunomodulatory Proteins (FIP-gsi) in Mouse Spleen Cells. Applied Biochemistry and Biotechnology 162, 1403-1413. 
Li W, Lou LL, Zhu JY, Zhang JS et al. 2016b - New lanostane-type triterpenoids from the fruiting body of Ganoderma hainanense. Fitoterapia 115, 24-30.

Li WJ, Chen Y, Nie SP, Xie MY et al. 2011a - Ganoderma atrum polysaccharide induces antitumor activity via the mitochondrial apoptotic pathway related to activation of host immune response. Journal of Cellular Biochemistry 112, 860-871.

Li WJ, Li L, Zhen WY, Wang LF et al. 2017a - Ganoderma atrum polysaccharide ameliorates ROS generation and apoptosis in spleen and thymus of immunosuppressed mice. Food and Chemical Toxicology 99, 199-208.

Li WJ, Nie SP, Chen Y, Yan Y. 2010a - Ganoderma atrum Polysaccharide Protects Cardiomyocytes against Anoxia/Reoxygenation-Induced Oxidative Stress by Mitochondrial Pathway. Journal of Cellular Biochemistry 110, 191-200.

Li WJ, Nie SP, Liu XZ, Zhang H et al. 2012b - Antimicrobial properties, antioxidant activity and cytotoxicity of ethanol-soluble acidic components from Ganoderma atrum. Food and Chemical Toxicology 50, 689-694.

Li WJ, Nie SP, Peng XP, Liu XZ. 2012a - Ganoderma atrum polysaccharide improves age-related oxidative stress and immune impairment in mice. Journal of Agricultural and Food Chemistry 60, 1413-1418.

Li WJ, Nie SP, Xie MY. 2011b - Ganoderma atrum polysaccharide attenuates oxidative stress induced by D-galactose in mouse brain. Life Sciences 88, 713-718.

Li WJ, Nie SP, Yan Y, Zhu SB et al. 2009 - The protective effect of Ganoderma atrum polysaccharide against anoxia/reoxygenation injury in neonatal rat cardiomyocytes. Life Sciences 85, 634-641.

Li WJ, Nie SP, Yao YF, Liu XZ et al. 2015 - Ganoderma atrum polysaccharide ameliorates hyperglycemia-induced endothelial cell death via a mitochondria-ROS pathway. Journal of Agricultural and Food Chemistry 63, 8182-8191.

Li WJ, Tang XF, Shuai XX, Jiang CJ et al. 2017b - Mannose Receptor Mediates the Immune Response to Ganoderma atrum Polysaccharides in Macrophages. Journal of Agricultural and Food Chemistry 65, 348-357.

Liao CH, Hsiao YM, Hsu CP, Lin MY et al. 2006 - Transcriptionally mediated inhibition of telomerase of fungal immunomodulatory protein from Ganoderma tsugae in A549 human lung adenocarcinoma cell line. Molecular Carcinogenesis 45, 220-229.

Liao CH, Hsiao YM, Lin CH, Yeh CS et al. 2008 - Induction of premature senescence in human lung cancer by fungal immunomodulatory protein from Ganoderma tsugae. Food and Chemical Toxicology 46, 1851-1859.

Liao CH, Hsiao YM, Sheu GT, Chang JT et al. 2007 - Nuclear translocation of telomerase reverse transcriptase and calcium signaling in repression of telomerase activity in human lung cancer cells by fungal immunomodulatory protein from Ganoderma tsugae. Biochemical Pharmacology 74, 1541-1554.

Lin CH, Sheu GT, Lin YW, Yeh CS et al. 2010 - A new immunomodulatory protein from Ganoderma microsporum inhibits epidermal growth factor mediated migration and invasion in A549 lung cancer cells. Process Biochemistry 45, 1537-1542.

Lin CN, Fann YF, Chung MI. 1997 - Steroids of Formosan Ganoderma tsugae. Phytochemistry 46, 1143-1146.

Lin CN, Tome WP, Won SJ. 1991 - Novel cytotoxic principles of Formosan Ganoderma lucidum. Journal of Natural Products 54, 998-1002.

Lin J, Lin C, Chen M, Ujiie T et al. 1995 - Radical scavenger and antihepatotoxic activity of Ganoderma formosanum, Ganoderma lucidum and Ganoderma neo-japonicum. Journal of Ethnopharmacology 47, 33-41.

Lin JM, Lin CC, Chiu HF, Yang JJ et al. 1993 - Evaluation of the anti-inflammatory and liverprotective effects of Anoectochilus formosanus, Ganoderma lucidum and Gynostemma pentaphyllum in rats. The American Journal of Chinese Medicine 21, 59-69. 
Lin JY, Chen ML, Chiang BL, Lin BF. 2006 - Ganoderma tsugae supplementation alleviates bronchoalvelar inflammation in an airway sensitization and challenge mouse model. International Immuno-pharmacology 6, 241-251.

Lin KW, Chen YT, Yang SC, Wei BL et al. 2013 - Xanthine oxidase inhibitory lanostanoids from Ganoderma tsugae. Fitoterapia 89, 231-238.

Lin KW, Maitrae D, Huang AM, Wang JP et al. 2016 - Triterpenoids and an alkamide from Ganoderma tsugae. Fitoterapia 108, 73-80.

Lin SB, Li CH, Lee SS, Kan LS. 2003 - Triterpene-enriched extracts from Ganoderma lucidum inhibit growth of hepatoma cells via suppressing protein kinase $\mathrm{C}$, activating mitogenactivated protein kinases and G2-phase cell cycle arrest. Life Sciences 72, 2381-2390.

Lin X, Farooqi AA, Ismail M. 2015 - Recent progress in fungus-derived bioactive agents for targeting of signaling machinery in cancer cells. Drug Design, Development and Therapy 9, 1797-1804.

Liu C, Zhao F, Chen RY. 2010 - A novel alkaloid from the fruiting bodies of Ganoderma sinense Zhao, Xu et Zhang. Chinese Chemical Letters 21, 197-199.

Liu JQ, Wang CF, Li Y, Luo HR et al. 2012 - Isolation and bioactivity evaluation of terpenoids from the medicinal fungus Ganoderma sinense. Planta Medica 78, 368-376.

Liu JQ, Wang CF, Peng XR, Qiu MH. 2011 - New alkaloids from the fruiting bodies of Ganoderma sinense. Natural Products and Bioprospecting 1, 93-96.

Liu LY, Chen H, Liu C, Wang HQ et al. 2014 - Triterpenoids of Ganoderma theaecolum and their hepatoprotective activities. Fitoterapia 98, 254-259.

Liu X, Xu SP, Wang JH. 2007 - Characterization of Ganoderma spore lipid by stable carbon isotope analysis: implications for authentication. Analytical and Bioanalytical Chemistry 388, 723-731.

Liu Y, Zhao C, Lin D, Lin H et al. 2015a - Effect of water extract from spent mushroom substrate after Ganoderma balabacense cultivation by using JUNCAO technique on production performance and hematology parameters of dairy cows. Animal Science Journal 86, 855-862.

Liu YH, Lin YS, Lin KL, Lu YL et al. 2015b - Effects of hot water extracts from Ganoderma lucidum residues and solid-state fermentation residues on prebiotic and immune-stimulatory activities in vitro and the powdered residues used as broiler feed additives in vivo. Botanical Studies 56, 17.

Liu YW, Gao JL, Guan J, Qian ZM et al. 2009 - Evaluation of Antiproliferative Activities and Action Mechanisms of Extracts from Two Species of Ganoderma on Tumor Cell Lines. Journal of Agricultural and Food Chemistry 57, 3087-3093.

Liu ZH, Hou XG, Zhao JH, HE L. 2015c - Liquid Fermentation of Ganoderma applanatum and Antioxidant Activity of Exopolysaccharides. The Open Biomedical Engineering Journal 9, 224-227.

Luna-Acosta A, Saulnier D, Pommier M, Haffner P et al. 2011 - First evidence of a potential antibacterial activity involving a laccase-type enzyme of the phenoloxidase system in Pacific oyster Crassostrea gigas haemocytes. Fish Shellfish Immunology 6, 795-800.

Luo Q, Di L, Dai WF, Lu Q et al. 2015 - Applanatumin A, a new dimeric meroterpenoid from Ganoderma applanatum that displays potent antifibrotic activity. Organic Letters 17, 11101113.

Luo Q, Wei XY, Yang J, Luo JF et al. 2017 - Spiro Meroterpenoids from Ganoderma applanatum. Journal of Natural Products 80, 61-70.

Ma JQ, Liu CM, Qin ZH, Jiang JH et al. 2011 - Ganoderma applanatum terpenes protect mouse liver against benzo $(\alpha)$ pyren-induced oxidative stress and inflammation. Environmental Toxicology and Pharmacology 31, 460-468.

Ma K, Ren J, Han J. 2014 - Ganoboninketals A-C, antiplasmodial 3, 4-seco-27-norlanostane triterpenes from Ganoderma boninense Pat. Journal of Natural Products 77, 1847-1852. 
Ma QY, Luo Y, Huang SZ, Guo ZK et al. 2013 - Lanostane triterpenoids with cytotoxic activities from the fruiting bodies of Ganoderma hainanense. Journal of Asian Natural Products Research 15, 1214-1219.

Mahmoud YAG, Mohamed EHFA, AbdElzaher EHF. 2007 - Response of the higher basidiomycetic Ganoderma resinaceum to sodium chloride stress. Mycobiology 35, 124-128.

Manayi A, Vazirian M, Zade FH, Tehranifard A. 2016 - Immunomodulation Effect of Aqueous Extract of the Artist's Conk Medicinal Mushroom Ganoderma applanatum (Agaricomycetes), on the Rainbow Trout (Oncorhynchus mykiss). International Journal of Medicinal Mushrooms 18, 927-933.

Mau JL, Lin HC, Song SF. 2002 - Antioxidant properties of several specialty mushrooms. Food Research International 35, 519-526.

Mau JL, Tsai SY, Tseng YH, Huang SJ. 2005a - Antioxidant properties of hot water extracts from Ganoderma tsugae Murrill. LWT - Food Science and Technology 38, 589-597.

Mau JL, Tsai SY, Tseng YH, Huang SJ. 2005b - Antioxidant properties of methanolic extracts from Ganoderma tsugae. Food Chemistry 93, 641-649.

Mendoza G,Suárez-Medellín J, Espinoza C, Ramos-Ligonio A et al. 2015 - Isolation and Characterization of Bioactive Metabolites from Fruiting Bodies and Mycelial Culture of Ganoderma oerstedii (Higher Basidiomycetes) from Mexico. International Journal of Medicinal Mushrooms 17, 501-509.

Ming D, Chilton J, Fogarty F, Towers GH. 2002 - Chemical constituents of Ganoderma applanatum of British Columbia forests. Fitoterapia 73, 147-152.

Mizuno T, Suuzki E, Maki K, Tamaki H. 1985 - Fractionation, chemical modification and antitumor activity of water soluble polysaccharides of the fruiting body of Ganoderma lucidum. Nippon Nokeikagaku Kaishi 59, 1143-1151.

Mizuno T. 1995 - Bioactive biomolecules of mushrooms: food function and medicinal effect of mushroom fungi. Food Reviews International 11, 5-21.

Mizushina Y, Takahashi N, Hanashima L, Koshino H et al. 1999 - Lucidenic acid O and lactone, new terpene inhibitors of eukaryotic DNA polymerases from a basidiomycete, Ganoderma lucidum. Bioorganic and Medicinal Chemistry 7, 2047-2052.

Moncalvo JM, Ryvarden L. 1997 - A nomenclatural study of the Ganodermataceae Donk. Fungi Flora 10, 1-114.

Moradali MF, Mostafavi H, Ghods S, Hedjaroude GA. 2007 - Immunomodulating and anticancer agents in the realm of macromycetes fungi (macrofungi). International Immunopharmacology 7, 701-724.

Mothana RAA, Awadh AAA, Jansen R, Wegner U et al. 2003 - Antiviral lanostanoid triterpenes from the fungus Ganoderma pfeifferi Bres. Fitoterapia 74, 177-180.

Mothana RAA, Jansen R, Jülich WD, Lindequist U. 2000 - Ganomycin A and B, new antimicrobial farnesyl hydroquinones from the basidiomycete Ganoderma pfeifferi. Journal of Natural Products 63, 416-418.

Mothana RAA. 1999 - Isolierung und Charakterisierung antibiotisch wirksamer Verbindungen aus Ganoderma pfeifferi Bres. dem Kupferroten Lackporling (Ph.D. Thesis). University of Greifswald, Germany.

Nakashima S, Umeda Y, Kanada T. 1979 - Effect of polysaccharides from Ganoderma applanatum on immune responses. I. Enhancing effect on the induction of delayed hypersensitivity in mice. Microbiology and Immunology 23, 501-513.

Ngai HK, Ng TB. 2004 - A mushroom (Ganoderma capense) lectin with spectacular thermostability, potent mitogenic activity on splenocytes, and antiproliferative activity toward tumor cells. Biochemical and Biophysical Research Communications 314, 988-993.

Niedermeyer TH, Jira T, Lalk M, Lindequist U. 2013 - Isolation of farnesyl hydroquinones from the basidiomycete Ganoderma pfeifferi. Natural Products and Bioprospecting 3, 137-140.

Niedermeyer TH, Lindequist U, Mentel R, Gördes D et al. 2005 - Antiviral Terpenoid Constituents of Ganoderma p feifferi. Journal of Natural Products 68, 1728-1731. 
Nishitoba T, Goto S, Sato H, Sakamura S, 1989 - Bitter triterpenoids from the fungus Ganoderma applanatum. Phytochemistry 28, 193-197.

Niu XM, Li SH, Sun HD, Che CT. 2006 - Prenylated phenolics from Ganoderma fornicatum. Journal of Natural Products 69, 1364-1365.

Niu XM, Li SH, Xiao WL, Sun HD et al. 2007 - Two new lanostanoids from Ganoderma resinaceum. Journal of Asian Natural Products Research 9, 659-664.

Niu XM, Qiu MH, Li ZR, Lu Y et al. 2004 - Two novel 3, 4-seco-trinorlanostane triterpenoids isolated from Ganoderma fornicatum. Tetrahedron Letters 45, 2989-2993.

Ofodile LN, Uma N, Grayer RJ, Ogundipe OT et al. 2012 - Antibacterial compounds from the mushroom Ganoderma colossum from Nigeria. Phytotherapy Research 26, 748-751.

Osińska-Jaroszuk M, Jaszek M, Mizerska-Dudka M, Błachowicz A et al. 2014 Exopolysaccharide from Ganoderma applanatum as a promising bioactive compound with cytostatic and antibacterial properties. BioMed Research International 1-10.

Park EJ, Lee WY. 2010 - Tryptophan enhanced accumulation of phenolic compounds via chorismate mutase activation in the Ganoderma neo-japonicum mycelia. Journal of the Korean Society for Applied Biological Chemistry 53, 364-370.

Paterson RRM. 2006 - Ganoderma - a therapeutic fungal bio factory. Photochemistry 67, 19852001.

Peng R, Fu Y, Zou J, Qiu H et al. 2016 - Improvement of polysaccharide and triterpenoid production of Ganoderma lucidum through mutagenesis of protoplasts. Biotechnology \& Biotechnological Equipment 30, 381-387.

Peng XR, Liu JQ, Han ZH, Yuan XX. 2013 - Protective effects of triterpenoids from Ganoderma resinaceum on $\mathrm{H}_{2} \mathrm{O}_{2}$-induced toxicity in HepG2 cells. Food Chemistry 141, 920-926.

Peng XR, Liu JQ, Wang CF, Li XY et al. 2014 - Hepatoprotective effects of triterpenoids from Ganoderma cochlear. Journal of Natural Products 77, 737-743.

Peng XR, Liu JQ, Xia JJ, Wang CF et al. 2015a - Lanostane triterpenoids from Ganoderma hainanense J. D. Zhao. Phytochemistry 114, 137-145.

Peng XR, Liu JQ, Xia JJ, Yang YH et al. 2012 - Two new triterpenoids from Ganoderma cochlear. Chinese Traditional and Herbal Drugs 43, 1045-1049.

Peng XR, Wang X, Zhou L, Hou B et al. 2015b - Ganocochlearic acid A, a rearranged hexanorlanostane triterpenoid, and cytotoxic triterpenoids from the fruiting bodies of Ganoderma cochlear. RSC Advances 5, 95212-95222.

Peng Y, Zhang L, Zeng F, Kennedy JF. 2005 - Structure and antitumor activities of the watersoluble polysaccharides from Ganoderma tsugae mycelium. Carbohydrate Polymers 59, 385392.

Peng Y, Zhang L, Zeng F, Xu Y. 2003 - Structure and antitumor activity of extracellular polysaccharides from mycelium. Carbohydrate Polymers 54, 297-303.

Peng Y, Zhang L. 2003 - Characterization of a polysaccharide-protein complex from Ganoderma tsugae mycelium by size-exclusion chromatography combined with laser light scattering. Journal of Biochemical and Biophysical methods 56, 243-252.

Pi CC, Chu CL, Lu CY, Zhuang YJ et al. 2014a - Polysaccharides from Ganoderma formosanum function as a Th1 adjuvant and stimulate cytotoxic T cell response in vivo. Vaccine 32, 401408.

Pi CC, Wang HY, Lu CY, Lu FL et al. 2014b - Ganoderma formosanum polysaccharides attenuate Th2 inflammation and airway hyper responsiveness in a murine model of allergic asthma. Springer Plus 3, 297.

Pilotti CA. 2005 - Stem rots of oil palm caused by Ganoderma boninense: Pathogen biology and epidemiology. Mycopathologia 159, 129-137.

Prendecka M, Mlak R, Jaszek M, Osińska-Jaroszuk M et al. 2016 - Effect of exopolysaccharide from Ganoderma applanatum on the electrical properties of mouse fibroblast cells line L929 culture using an electric cell-substrate impedance sensing (ECIS) - Preliminary study. Annals of Agricultural and Environmental Medicine 23, 280-284. 
Qi ZH, Meng J, Wang ZL, Sun HZ et al. 2016 - Antitumor Effect of Ganoderma lipsiense Extract on Triple-negative Breast Cancer Model Mice and Mechanism Study. Chinese Journal of Integrated Traditional and Western medicine 36, 366-369.

Qiao Y, Zhang XM, Dong XC, Qiu MH. 2006 - A New 18(13 $\rightarrow$ 12ß) -abeo-Lanostadiene Triterpenoid from Ganoderma fornicatum. Helvetica Chimica Acta 89, 1038-1041.

Qiao Y, Zhang XM, Qiu MH. 2007 - Two novel lanostane triterpenoids from Ganoderma sinense. Molecules 12, 2038-2046.

Qiu J, Wang X, Song C. 2016 - Neuroprotective and antioxidant lanostanoid triterpenes from the fruiting bodies of Ganoderma atrum. Fitoterapia 109, 75-79.

Richter C, Wittstein K, Kirk MP, Stadler M. 2015 - An assessment of the taxonomy and chemotaxonomy of Ganoderma. Fungal Diversity 71, 1-15.

Rosecke J, Konig WA. 2000 - Constituents of various wood-rotting Basidiomycetes. Phytochemistry 54, 603-610.

Sasaki T, Arai Y, Ikekawa T, Chihara G et al. 1971 - Antitumor polysaccharides from some Polyporaceae, Ganoderma applanatum (Pers.) Pat and Phellinus linteus (Berk. et Curt) Aoshima. Chemical and Pharmaceutical Bulletin (Tokyo) 19, 821-826.

Sato N, Ma CM, Komatsu K, Hattori M. 2009a - Triterpene-farnesyl hydroquinone conjugates from Ganoderma sinense. Journal of Natural Products 72, 958-961.

Sato N, Zhang Q, Ma CM, Hattori M. 2009b - Anti-human immunodeficiency virus-1 protease activity of new lanostane-type triterpenoids from Ganoderma sinense. Chemical and Pharmaceutical Bulletin (Tokyo) 57, 1076-1080.

Schwarze FWMR, Ferner D. 2003 - Ganoderma on trees-differentiation of species and studies of invasiveness. Arboricultural Journal 27, 59-77.

Seong KE, Young SK, Chong KL, Seong SH. 2000 - Possible mode of antiviral activity of acidic protein bound polysaccharide isolated from Ganoderma lucidum on herpes simplex viruses. Journal of Ethnopharmacology 72, 475-481.

Seow SLS, Naidu M, David P, Wong KH et al. 2013 - Potentiation of neuritogenic activity of medicinal mushrooms in rat pheochromocytoma cells. BMC Complementary and Alternative Medicine 13, 157.

Shen M, Xie M, Nie S, Wang Y et al. 2008 - Separation and identification of Ergosta-4, 6, 8(14), 22-tetraen-3-one from Ganoderma atrum by High-Speed Counter-Current Chromatography and Spectroscopic Methods. Chromatographia 67, 999-1001.

Shiao MS. 2003 - Natural products of the medicinal fungus Ganoderma lucidum: occurrence, biological activities, and pharmacological functions. The Chemical Record 3, 172-180.

Shim SH, Ryu J, Kim JS, Kang SS et al. 2004 - New lanostane-type triterpenoids from Ganoderma applanatum. Journal of Natural Products 67, 1110-1113.

Shimizu A, Yano T, Saito Y, Inada Y. 1985 - Isolation of an inhibitor of platelet aggregation from a fungus, Ganoderma lucidum. Chemical and Pharmaceutical Bulletin 33, 3012-3015.

Singdevsachan SK, Patra JK, Tayung K. 2015 - Chemical Constituents, Antioxidative and Antibacterial Properties of Medicinal Mushrooms Collected from Similipal Biosphere Reserve, Odisha, India. Proceedings of the National Academy of Sciences, India Section B: Biological Sciences 1-12.

Smania AJ, Delle Monache F, Smania EFA, Cuneo RS. 1999 - Antibacterial activity of steroidal compounds isolated from Ganoderma applanatum (Pers.) Pat. (Aphyllophoromycetideae) fruit body. International Journal of Medicinal Mushrooms 1, 325-330.

Smania EFA, Delle Monache F, Smania A, Yunes RA et al. 2003 - Antifungal activity of sterols and triterpenes isolated from Ganoderma annulare. Fitoterapia 74, 375-377.

Smania EFA, Monache FDM, Yunes RA, Paulert R et al. 2007 - Antimicrobial activity of methyl australate from Ganoderma australe. Revista Brasileira de Farmacognosia 17, 14-16.

Strigina LI, Elkin YN, Elyakov GB. 1971 - Steroid metabolites of Ganoderma applanatum basidiomycete. Phytochemistry 10, 2361-2365. 
Su CH, Lai MN, Chan MH. 1993 - Hepato-protective triterpenoids from Ganoderma tsugae Murrill. In: Chang S, Buswell JA, Chiu S. (Eds) Mushroom Biology and Mushroom Products, The Chinese University Press, Hong Kong, China 275-283.

Su CY, Shiao MS, Wang CT. 1999 - Differential effects of Ganoderma acids on the thromboxane A 2-signaling pathways in human platelets. Biochemical Pharmacology 58, 587-595.

Su HJ, Fann YF, Chung MI, Won SJ et al. 2000 - New lanostanoids of Ganoderma tsugae. Journal of Natural Products 63, 514-516.

Subramaniam S, Sabaratnam V, Kuppusamy UR, Tan YS. 2014 - Solid-substrate fermentation of wheat grains by mycelia of indigenous species of the genus Ganoderma (higher Basidiomycetes) to enhance the antioxidant activities. International Journal of Medicinal Mushrooms 16, 259-267.

Subramaniam S, Sabaratnam V, Umah RK. 2015 - Solid-substrate fermentation of wheat grains by mycelia of indigenous Ganoderma spp. enhanced adipogenesis and modulated PPAR $\gamma$ expression in 3T3-L1 cells. Chiang Mai Journal of Science 42, 269-281.

Sun X, Wang H, Han X, Chen S et al. 2014 - Fingerprint analysis of polysaccharides from different Ganoderma by HPLC combined with chemometrics methods. Carbohydrate Polymers 114, 432-439.

Tan WC, Kuppusamy UR, Phan CW, Tan YS et al. 2015 - Ganoderma neo-japonicum Imazeki revisited: Domestication study and antioxidant properties of its basidiocarps and mycelia. Scientific Reports 5.

Teplyakova T, Kosogova TA. 2015 - Fungal bioactive compounds with antiviral effect. Journal of Pharmacy and Pharmacology 3, 357-371.

Thang TD, Kuo PC, Hwang TL, Yang ML et al. 2013 - Triterpenoids and Steroids from Ganoderma mastoporum and their inhibitory effects on Superoxide Anion Generation and Elastase release. Molecules 18, 14285-14292.

Tian CE, Tian R, Zhou Y, Chen Q et al. 2013 - Decolorization of indigo dye and indigo dyecontaining textile effluent by Ganoderma weberianum. African Journal of Microbiology Research 7, 941-947.

Tokuyama T, Takashi Y, Yoshinori, Nishizawa M et al. 1991 - Applanoxidic acids A, B, C and D, biologically active tetracyclic triterpenes from Ganoderma applanatum. Phytochemistry 30, 4105-4109.

Tran HB, Yamamoto A, Matsumoto S, Ito H et al. 2014 - Hypotensive effects and AngiotensinConverting enzyme inhibitory peptides of Reishi (Ganoderma lingzhi). Auto-Digested Extract. Molecules 19, 13473-13485.

Trigos A, Medellín JS. 2011 - Biologically active metabolites of the genus Ganoderma: Three decades of mycochemistry research. Revista Mexicana de Mycologia 34, 63-83.

Tseng CY, Chung MC, Wang JS, Chang YJ et al. 2016 - Potent in vitro protection against PM2.5Caused ROS generation and vascular permeability by long-term pretreatment with Ganoderma tsugae. The American Journal of Chinese Medicine 44, 355-376.

Tseng YH, Mau JL. 2007 - Antioxidant properties of cold water extracts from Ganoderma tsugae. Fungal Science 22, 15-25.

Tseng YH, Yang JH, Mau JL. 2008 - Antioxidant properties of polysaccharides from Ganoderma tsugae. Food Chemistry 107, 732-738.

Turner PD. 1981 - Incorporated Society of Planters. Oil palm diseases and disorders. Kuala Lumpur: Published for the Incorporated Society of Planters by Oxford University Press.

Ulbricht C, Isaac R, Milkin T, Poole E et al. 2010 - An evidence-based systematic review of stevia by the Natural Standard Research Collaboration. Cardiovascular \& Hematological Agents in Medicinal Chemistry 8, 113-127.

Usui T, Iwasaki Y, Mizuno T. 1983 - Isolation and characterization of antitumor active $\beta$-Dglucans from the fruit bodies of Ganoderma applanatum. Carbohydrate Research 115, 273 280 . 
Vazirian M, Dianat S, Manayi A, Ziari R et al. 2014 -Anti-inflammatory effect, total polysaccharide, total phenolics content and antioxidant activity of the aqueous extract of three basidiomycetes. Research Journal of Pharmacognosy 1, 13-19.

Wan F, Huang D. 1992 - Anti-inflammatory and analgesic actions of artificial and fermentative Ganoderma sinense (AFGS). China Journal of Chinese Materia Medica 17, 619-622.

Wang CF, Liu JQ, Yan YX, Chen JC et al. 2010 - Three new triterpenoids containing fourmembered ring from the fruiting body of Ganoderma sinense. Organic letters 12, 1656-1659.

Wang CL, Lu CY, Hsueh YC, Liu WH et al. 2014 - Activation of antitumor immune responses by Ganoderma formosanum polysaccharides in tumor-bearing mice. Applied Microbiology and Biotechnology 98, 9389-9398.

Wang CL, Lu CY, Pi CC, Zhuang YJ et al. 2012b - Extracellular polysaccharides produced by Ganoderma formosanum stimulate macrophage activation via multiple pattern-recognition receptors. BMC Complementary and Alternative Medicine 12, 119.

Wang CL, Pi CC, Kuo CW, Zhuang YJ et al. 2011 - Polysaccharides purified from the submerged culture of Ganoderma formosanum stimulate macrophage activation and protect mice against infection. Biotechnology Letters 33, 2271-2278.

Wang F, Liu JK. 2008 - Highly oxygenated lanostane type triterpenoids from the fungus Ganoderma applanatum. Chemistry and Pharmacology Bulletin 56, 1035-1037.

Wang G, Zhang J, Mizuno T, Zhuang C et al. 1993 - Antitumor active polysaccharides from the Chinese mushroom Songshan lingzhi, the fruiting body of Ganoderma tsugae. Bioscience, Biotechnology, and Biochemistry 57, 894-900.

Wang K, Bao L, Ma K, Zhang J et al. 2016d - A novel class of $\alpha$-glucosidase and HMG-CoA reductase inhibitors from Ganoderma leucocontextum and the anti-diabetic properties of ganomycin I in KK-Ay mice. European Journal of Medicinal Chemistry 127, 1035-1046.

Wang K, Bao L, Xiong WP, Ma K et al. 2015 - Lanostane Triterpenes from the Tibetan Medicinal Mushroom Ganoderma leucocontextum and their inhibitory effects on HMG-CoA Reductase and $\alpha$ Glucosidase. Journal of Natural Products 78, 1977-1989.

Wang M, Wang F, Xu F, Ding LQ et al. 2016a - Two pairs of farnesyl phenolic enantiomers as natural nitric oxide inhibitors from Ganoderma sinense. Bioorganic \& Medicinal Chemistry Letters 26, 3342-3345.

Wang PH, Yang SF, Chen GD, Han CP et al. 2007 - Human Nonmetastatic Clone 23 Type 1 Gene Suppresses Migration of Cervical Cancer Cells and Enhances the Migration Inhibition of Fungal Immunomodulatory Protein from Ganoderma tsugae. Reproductive Sciences 14, 475485.

Wang XC, Xi RJ, Li Y, Wang DM et al. 2012a - The species identity of the widely cultivated Ganoderma, 'G. lucidum' (Ling-zhi), in China. PLoS One 7, e40857.

Wang XL, Dou M, Luo Q, Cheng LZ et al. 2016c - Racemic alkaloids from the fungus Ganoderma cochlear. Fitoterapia 116, 93-98.

Wang XL, Zhou FJ, Dou M, Yan YM et al. 2016b - Cochlearoids F-K, Phenolic meroterpenoids from the fungus Ganoderma cochlear and their renoprotective activity.Bioorganic and Medicinal Chemistry Letters 26, 5507-5512.

Wasser SP, Weis AL. 1999 - General description of the most important medicinal higher basidiomycetes mushrooms. International Journal of Medicinal Mushrooms 1, 351-370.

Welti S, Moreau PA, Azaroual N, Lemoine A et al. 2010 - Antiproliferative activities of methanolic extracts from a neotropicalGanodermaspecies (Aphyllophoromycetideae): Identification and characterization of a novel ganoderic acid. International Journal of Medicinal Mushrooms 12, 17-31.

Wen Z, Li J, He S, Xiong S et al. 1997 - Effect of Ganoderma japonicum (Fr.) Lloyd mixture on experimental thrombosis. Hunan Yi Ke Da Xue Xue Bao 22, 15-18 (in Chinese).

Weng CJ, Fang PS, Chen DH, Chen KD et al. 2010 - Anti-invasive effect of a rare mushroom, Ganoderma colossum, on human hepatoma cells. Journal of Agricultural and Food Chemistry $58,7657-7663$. 
Won SJ, Lin MT, Wu WL. 1992 - Ganoderma tsugae Mycelium Enhances Splenic Natural Killer Cell Activity and Serum Interferon Production in Mice. The Japanese Journal of Pharmacology 59, 171-176.

Wu YW, Chen KD, Lin WC. 2004 - Effects of Ganoderma tsugae on chronically carbon tetrachloride-intoxicated rats. American Journal of Chinese Medicine 32, 841-850.

$\mathrm{Xu} \mathrm{H}$, Kong YY, Chen X, Guo MY et al. 2016 - Recombinant FIP-gat, a Fungal Immunomodulatory Protein from Ganoderma atrum, Induces Growth Inhibition and Cell Death in Breast Cancer Cells. Journal of Agricultural and Food Chemistry 64, 2690-2698.

Yan YM, Ai J, Zhou LL, Chung AC et al. 2013 - Lingzhiols, unprecedented rotary door-shaped meroterpenoids as potent and selective inhibitors of p-Smad3 from Ganoderma lucidum. Organic Letters 15, 5488-5491.

Yan YM, Wang XL, Luo Q, Jiang LP et al. 2015 - Metabolites from the mushroom Ganoderma lingzhi as stimulators of neural stem cell proliferation. Phytochemistry 114, 155-162.

Yang H. 2005 - Ganoderic acid produced from submerged culture of Ganoderma lucidum induces cell cycle arrest and cytotoxicity in human hepatoma cell line BEL7402. Biotechnology Letters 27, 835-838.

Yang JJ, Yu DQ. 1990 - Synthesis of Ganoderma alkaloid A and B. Acta Pharmaceutica Sinica 25, $555-559$.

Yang S, Ma QY, Huang SZ, Dai HF et al. 2014 - Chemical constituents from Ganoderma philippii. China Journal of Chinese Materia Medica 39, 1034-1039.

Yang SX, Yu ZC, Lu QQ, Shi WQ et al. 2012 - Toxic lanostane triterpenes from the basidiomycete Ganoderma amboinense. Phytochemistry Letters 5, 576-580.

Yang Y, Yang Z, Cheng CR, Qing FL. 2013 - Synthesis and anti-tumor activity evaluation of gamma-Monofluorinated and gamma, gamma-Difluorinated Goniothalamin Analogues. Chinese Journal of Chemistry 31, 805-812.

Yen GC, Wu JY. 1999 - Antioxidant and radical scavenging properties of extracts from Ganoderma tsugae. Food Chemistry 65, 375-379.

Yoshikawa K, Nishimura N, Bando S. 2002 - New lanostanoids, elfvingic acids A-H, from the fruit body of Elfvingia applanata. Journal of Natural products 65, 548-552.

Yu JG, Chen RY, Yao ZX, Zhai YF et al. 1990 - Studies on constituents of Ganoderma capense IV. The chemical structures of ganoine, ganodine and ganoderpurine. Acta Pharmaceutica Sinica 25, 612-616.

Yu Q, Nie SP, LI WJ, Zheng WY et al. 2012a - Macrophage Immunomodulatory Activity of a Purified Polysaccharide Isolated from Ganoderma atrum. Phytotherapy Research. doi: 10.1002/ptr.4698.

Yu Q, Nie SP, Wang JQ, Huang DF et al. 2015 - Toll-like receptor 4 mediates the antitumor host response induced by Ganoderma atrum polysaccharide. Journal of Agricultural and Food Chemistry 63, 517-525.

Yu Q, Nie SP, Wang JQ, Liu XZ et al. 2014b - Chemoprotective effects of Ganoderma atrum polysaccharide in cyclophosphamide-induced mice. International Journal of Biological Macromolecules 64, 395-401.

Yu Q, Nie SP, Wang JQ, Yin PF et al. 2014a - Toll-like receptor 4-mediated ROS signaling pathway involved in Ganoderma atrum polysaccharide-induced tumor necrosis factor- $\alpha$ secretion during macrophage activation. Food and Chemical Toxicology 66, 14-22.

Yu Q, Nie SP, Wang JQ, Yin PF et al. 2012a - Polysaccharide from Ganoderma atrum induces tumor necrosis factor- $\alpha$ secretion via phosphoinositide 3-kinase/Akt, mitogen-activated protein kinase and nuclear factor- $\kappa \mathrm{B}$ signaling pathways in RAW264.7 cells. International Immunopharmacology 14, 362-368.

Yu YH, Kuo HP, Hsieh HH, Li JW et al. 2012b - Ganoderma tsugae Induces S Phase Arrest and Apoptosis in Doxorubicin-Resistant Lung Adenocarcinoma H23/0.3 Cells via Modulation of the PI3K/Akt Signaling Pathway. Evidence-Based Complementary and Alternative Medicine 2012. doi:10.1155/2012/371286. 
Yue GF, Tse KP, Leung GMK, Lau CBS. 2006 - Comparative studies of various Ganoderma species and their different parts with regard to their antitumor and immunomodulating activities in vitro. Journal of Alternative \& Complementary Medicine 12, 777-789.

Yue GG, Chan BC, Han XQ, Cheng L et al. 2013 - Immunomodulatory activities of Ganoderma sinense polysaccharides in human immune cells. Nutrition and Cancer 65, 765-774.

Yue GG, Fung KP, Leung PC, Lau CB. 2008 - Comparative studies on the immunomodulatory and antitumor activities of the different parts of fruiting body of Ganoderma lucidum and Ganoderma spores. Phytotherapy Research 22, 1282-1291.

Zengin G, Sarikurkcu C, Gunes E, Uysal A et al. 2015 - Two Ganoderma species: profiling of phenolic compounds by HPLC-DAD, antioxidant, antimicrobial and inhibitory activities on key enzymes linked to diabetes mellitus, Alzheimer's disease and skin disorders. Food \& Function 6, 2794-2802.

Zhang DH, Li N, Yu X, Zhao P et al. 2017 - Overexpression of the homologous lanosterol synthase gene in ganoderic acid biosynthesis in Ganoderma lingzhi. Phytochemistry 134, 4653.

Zhang J, Wang G, Li H, Zhuang C et al. 1994 - Antitumor active protein-containing glycans from the Chinese mushroom songshan lingzhi, Ganoderma tsugae mycelium. Bioscience, Biotechnology, and Biochemistry 58, 1202-1205.

Zhang S, Nie S, Huang D, Huang J et al. 2014 - A polysaccharide from Ganoderma atrum inhibits tumor growth by induction of apoptosis and activation of immune response in CT26-bearing mice. Journal of Agricultural and Food chemistry 62, 9296-9304.

Zhang S, Nie S, Huang D, Huang J et al. 2013a - Polysaccharide from Ganoderma atrum evokes antitumor activity via Toll-like receptor 4-mediated NF- $\kappa \mathrm{B}$ and mitogen-activated protein kinase signaling pathways. Journal of agricultural and food chemistry 61, 3676-3682.

Zhang SS, Wang YG, Ma QY, Huang SZ et al. 2015 - Three new Lanostanoids from the mushroom Ganoderma tropicum. Molecules 20, 3281-3289.

Zhao ZZ, Chen HP, Huang Y, Li ZH et al. 2016a - Lanostane Triterpenoids from Fruiting Bodies of Ganoderma leucocontextum. Natural Products and Bioprospecting 6, 103-109.

Zhao ZZ, Chen HP, Li ZH, Dong ZJ et al. 2016b - Leucocontextins A-R, lanostane-type triterpenoids from Ganoderma leucocontextum. Fitoterapia 109, 91-98.

Zheng K, Zhang J, Lin XY, Li FL et al. 2005 - Anti mutagenic effect of polysaccharides from antimutagenic effect of polysaccharides from Ganoderma tsugae. Journal of Jilin University 43, 235-237.

Zhou LW, Cao, Y, Wu SH, Vlasák J et al. 2015a - Global diversity of the Ganoderma lucidum complex (Ganodermataceae, Polyporales) inferred from morphology and multilocus phylogeny. Phytochemistry 114, 7-15.

Zhou XW, Su KQ, Zhang YM. 2011a - Applied modern biotechnology for cultivation of Ganoderma and development of their products. Applied Microbiology and Biotechnology 93, 941-963.

Zhou Y, Chen S, Ding R, Yao W et al. 2014 - Inflammatory Modulation Effect of Glycopeptide from Ganoderma capense (Lloyd) Teng. Mediators of Inflammation Article ID 691285, 8.

Zhou YP, Chen MH, Lu JJ, Kang X et al. 2015b - A simple and efficient genetic transformation method of Ganoderma weberianum. Folia Microbiologica 60, 417-423.

Zhou YP, Chen QH, Cheng HZ, Gui L et al. 2011b - Decolorization of indigo carmine by Ganoderma weberianum. Advanced Materials Research 183, 1035-1040.

Zhu K, Nie S, Li C, Gong D et al. 2014 - Ganoderma atrum polysaccharide improves aortic relaxation in diabetic rats via PI3K/Akt pathway. Carbohydrate Polymers 103, 520-527.

Zhu K, Nie S, Li C, Xie M. 2013 - A newly identified polysaccharide from Ganoderma atrum attenuates hyperglycemia and hyperlipidemia. International Journal of Biological Macromolecules 57, 142-150. 
Zhu KX, Nie SP, Tan LH, Li C et al. 2016 - A polysaccharide from Ganoderma atrum improves liver function in Type 2 Diabetic Rats via antioxidant action and short-chain fatty acids excretion. Journal of Agricultural and Food Chemistry 64, 1938-1944.

Zjawiony JK. 2004 - Biologically active compounds from Aphyllophorales (Polypore) fungi. Journal of Natural Products 67, 300-310. 